NASA Technical Memorandum 106971

AIAA-95-2614

\title{
Validation of the NPARC Code for Nozzle Afterbody Flows at Transonic Speeds
}

James R. DeBonis and Nicholas J. Georgiadis

Lewis Research Center

Cleveland, Ohio

Crawford F. Smith

NYMA, Inc.

Brook Park, Ohio

Prepared for the

31st Joint Propulsion Conference and Exhibit cosponsored by AIAA, ASME, SAE, and ASEE

San Diego, California, July 10-12, 1995

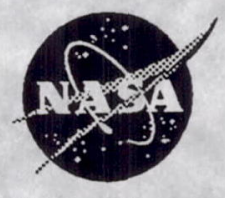

National Aeronautics and

Space Administration 


\title{
VALIDATION OF THE NPARC CODE FOR NOZZLE AFTERBODY FLOWS AT TRANSONIC SPEEDS
}

\author{
James R. DeBonis and Nicholas J. Georgiadis \\ National Aeronautics and Space Administration \\ Lewis Research Center \\ Cleveland, Ohio 44135 \\ and \\ Crawford F. Smith \\ NYMA, Inc. \\ Brookpark, Ohio 44107
}

\begin{abstract}
SUMMARY
The NPARC code, a Reynolds-averaged full Navier-Stokes code, was validated for nozzle afterbody (boattail) flow fields at transonic speeds. The flow fields about three geometries were studied: an axisymmetric nozzle with attached flow; an axisymmetric nozzle with separated flow; and a two-dimensional (rectangular) nozzle with separated flow. Three turbulence models, Baldwin-Lomax, Baldwin-Barth, and Chien $\mathrm{k}-\varepsilon$, were used to determine the effect of turbulence model selection on the flow field solution. Static pressure distributions on the nozzle surfaces and pitot pressure measurements in the exhaust plume were examined. Results from the NPARC code compared very well with experimental data for all cases. For attached flow fields, the effect of the turbulence models showed no discernable differences. The BaldwinBarth model yielded better results than either the Chien $k-\varepsilon$ or the Baldwin-Lomax model for separated flow fields.
\end{abstract}

\section{INTRODUCTION}

Research to support the development of a supersonic cruise passenger aircraft is underway throughout the world. In the United States, the National Aeronautics and Space Administration (NASA) is developing the enabling technologies for such an aircraft under the High Speed Research (HSR) program. One of the most critical of these technologies is the propulsion system. The propulsion system must operate efficiently throughout the flight regime from take-off to supersonic cruise and integrate well with the rest of the vehicle.

At transonic speeds, the drag on the nozzle afterbody (boattail) can account for a significant portion of the total aircraft drag. Therefore, reduction of transonic boattail drag can greatly improve the performance of a supersonic aircraft. Determining boattail drag of potential nozzle configurations through wind tunnel tests is difficult at transonic conditions because of tunnel interference effects. An alternative to nozzle testing is the application of computational fluid dynamics (CFD) techniques that numerically model the boattail flow field. However, CFD codes must be validated with experimental data before they can be expected to provide accurate drag predictions.

Work performed at the NASA Lewis Research Center to validate the NPARC CFD code (ref. 1) for the transonic nozzle afterbody problem is reported herein. The study compares CFD predictions to test data for three nozzle geometries. Two of the selected nozzle geometries were also used as part of a validation study sponsored by the Advisory Group for Aerospace Research and Development (AGARD) Working Group \#17 (ref. 2). 


\section{SYMBOLS}

A

area

$\mathrm{C}_{\mathrm{p}}$ pressure coefficient; $\mathrm{C}_{\mathrm{p}}=\frac{\mathrm{p}-\mathrm{p}_{\infty}}{\mathrm{q}_{\infty}}$

D nozzle exit diameter

L length of model

M Mach number

NPR nozzle pressure ratio; NPR $=\frac{\mathrm{p}_{0_{j}}}{\mathrm{p}_{\infty}}$

p pressure

q dynamic pressure

r radius

$\mathrm{T}$ temperature

$x \quad$ axial distance from model nose

Subscript:

j jet

$t$ pitot

0 stagnation condition

8 nozzle throat station

9 nozzle exit station

$\infty \quad$ freestream condition

\section{NPARC CODE}

The NPARC code is a general purpose computational fluid dynamics (CFD) code that is widely used in government, industry, and academia for fluid flow simulations, particularly of aircraft propulsion systems components. The code is actively supported by the NPARC Alliance, a partnership between NASA Lewis Research Center and the Arnold Engineering Development Center, Air Force Material Command. NPARC is a general CFD engineering tool applicable to a wide range of flow problems. The code is very robust and user friendly.

NPARC solves the Reynolds-averaged Navier-Stokes equations in strong conservation law form by using the Beam-Warming approximate factorization algorithm (ref. 3). Spatial discretization is performed by using a central difference scheme. Jameson-style artificial dissipation is added for stability and to smooth shock oscillations and odd-even grid point decoupling (ref. 4).

NPARC is very flexible in handling computational grids. The code lets the user specify a boundary condition on any portion of any grid surface, allowing a complex geometry to be handled by using one grid block. The code can also use grids subdivided into multiple grid blocks. Grid points may or may not be contiguous across the block interface. For a noncontiguous interface, the code uses a trilinear interpolation scheme to pass data through the boundary.

The code has several options for modeling turbulence varying from algebraic (zero transport equations) to one- and two-equation models. Three turbulence models were used for the boattail nozzle calculations discussed in this report: (1) the Baldwin-Lomax algebraic turbulence model (ref. 5), which was optimized for attached wall-bounded flows; (2) the Baldwin-Barth one-equation turbulence model (ref. 6), which solves a transport equation for the turbulent Reynolds number; and (3) the Chien k- $\varepsilon$ low-Reynolds number model 
(ref. 7), which solves two transport equations, one for the turbulent kinetic energy, and the other for the rate of turbulent kinetic energy dissipation.

Convergence of the code was determined by monitoring L2 residual error, nozzle mass flow rate, and afterbody pressure coefficients. Convergence occurred when the L2 residual error was reduced at least three orders of magnitude, and when the change in nozzle mass flow rate and afterbody pressure coefficients over one thousand iterations was less than one percent.

\section{DISCUSSION OF FLOW CASES}

\section{Case 1: Axisymmetric Nozzle; Attached Flow}

Nozzle Description.-The first nozzle studied was an axisymmetric configuration (see fig. 1) used in the AGARD study and designated B1. This nozzle was tested in the 16-Foot Transonic Wind tunnel at the NASA Langley Research Center by Henderson and Burley (ref. 8). The data consist of pressure distributions on the nozzle afterbody for freestream Mach numbers between 0.60 and 1.20, nozzle pressure ratios between 1.00 and 8.00 , and angles of attack between $-3.0^{\circ}$ and $6.0^{\circ}$. The flow remained attached to the body for the conditions investigated in this report. The nozzle was installed on the aft end of a generic axisymmetric forebody. The forebody consisted of an ogive nose followed by an afterbody section that smoothly transitioned into the large radius boattail. The final boattail angle was $20^{\circ}$. The internal nozzle contour was a convergentdivergent design with an $A_{9} / A_{8}=1.02$. The model was mounted in the tunnel on a sting-strut arrangement. The boundary layer on the model was tripped $2.25 \mathrm{in}$. downstream of the nose to ensure turbulent flow over the test article.

Computational Grid.-The grid for this case was provided by the McDonnell Douglas Aircraft Company. It was modified slightly for use with the NPARC code by creating grid overlap at each block interface. This was done by adding an additional grid line at the boundary that extended into the adjacent grid block. The grid modeled the entire forebody, nozzle afterbody, internal nozzle, and plenum (fig. 2(a)). The support strut and sting were not modeled. The grid boundaries were approximately one body length away from the geometry in all directions: upstream of the model's nose, downstream of the nozzle exit, and above the model centerline. Figure 2(b) shows a detailed view of the grid in the area of greatest interest, around the nozzle afterbody and internal nozzle. The grid was constructed in four blocks: an upstream section including the forward portion of the model; a boattail section; an internal nozzle section; and a downstream section to capture the exhaust plume (fig. 2(c)). The total number of grid points used was 11647 ; table I contains the dimensions of the individual grid blocks.

Results. - Four solutions were obtained for this geometry at two nozzle pressure ratios (NPR). The effect of turbulence model selection was investigated at an NPR of 2.033. Three models were assessed: the Baldwin-Lomax algebraic model; the Baldwin-Barth one-equation model; and the Chien k- $\varepsilon$ two-equation model. The Baldwin-Barth model was used for the solution at an NPR of 4.991. The external Mach number for these cases was 0.901 . Table II summarizes the flow field conditions. The data for this case were taken at several circumferential locations. For the purpose of comparison with the CFD predictions, the data plotted were at a circumferential location opposite the support strut.

NPR $=2.033$ : Figure 3 shows Mach number contours for an NPR of 2.033. At this condition, the nozzle operated slightly overexpanded. The internal nozzle contours show a curved sonic line at the nozzle throat. The flow then expands supersonically to the exit where a weak shock wave recompresses the flow. The external contours indicate that the flow decelerates aft of the boattail shoulder. Despite the flow deceleration caused by an adverse pressure gradient, the flow remains attached to the afterbody surface.

Pressure coefficient distributions on the afterbody surface, obtained with all three turbulence models, are compared with experimental data in figure 4 . Overall agreement with the data is very good for all three models. However, the code consistently underpredicts the minimum pressure coefficient at an $\mathrm{x} / \mathrm{L}=0.93$ and overpredicts the recompression near the end of the afterbody. The Baldwin-Lomax and Baldwin-Barth predictions are essentially the same. Although the Chien $k-\varepsilon$ model predicts pressure coefficients over the last 20 percent of the body that are slightly higher than the other models, its agreement with experimental data is still considered good.

NPR $=4.991:$ The Baldwin-Barth turbulence model was selected for the NPR of 4.991 analysis because it had the best agreement with experimental data in the lower pressure ratio (NPR $=2.033$ ) analysis. Mach number contours for an NPR of 4.991 indicate that the nozzle operated at an underexpanded 
condition (fig. 5.). A series of expansion waves emanate from the nozzle lip. Also, the exhaust plume rapidly expands outward at the exit. An oblique shock occurs approximately 1.4 nozzle diameters downstream of the exit plane.

The external Mach number contours indicate a flow deceleration on the boattail surface similar to the $\mathrm{NPR}=2.033$ case. The underexpanded jet pressurizes the boattail surface creating a larger area of low speed flow at the nozzle exit plane.

Figure 6 shows a comparison of the NPARC prediction and experimental measurements. Agreement between experimental and computational pressure distributions is very good.

The effect of the underexpanded jet can be seen by comparing the pressure distributions on the afterbody surface at both nozzle pressure ratios (fig. 7.). The pressure coefficient on the aft portion of the boattail is higher for the underexpanded jet.

\section{Case 2: Axisymmetric Nozzle; Separated Flow}

Nozzle Description. - The flow over many nozzle boattail configurations separates from the surface because of the large adverse pressure gradient over the aft portion of the nozzle. In order to investigate the NPARC code's performance for such a case, a second axisymmetric geometry with a separated flow field was analyzed. The chosen nozzle was also tested at the NASA Langley 16-Foot Transonic Wind Tunnel and its geometry is shown in figure 8. Surface static pressure measurements were made by Abeyounis and Putnam (ref. 9). Mason and Putnam (ref. 10) reported pitot pressure measurements in the exhaust plume. Data were taken at freestream Mach numbers of 0.4, 0.6, and 0.8, and at NPR's of 2.0, 2.9, and 5.0. The nozzle was installed on the aft end of a generic axisymmetric forebody consisting of a conical nose followed by a straight afterbody section. The boattail shape was defined by a circular radius starting at the nozzle shoulder and had a final angle of approximately $30^{\circ}$. The model was mounted in the tunnel on a sting-strut arrangement. The boundary layer on the model was tripped 1 in. downstream of the nose to ensure turbulent flow over the test article. The internal nozzle contour is a convergent design.

Computational Grid.-The grid for this case was generated by using the GENIE3D code developed by Soni (ref. 11). The grid included the entire forebody, afterbody, internal nozzle, and plenum (fig. 9). The support strut and sting were not modeled. The upstream grid boundary was placed approximately one half of a model length from the nose of the test article; and the downstream grid boundary, approximately two model lengths downstream of the nozzle exit. The upper boundary was about one half of a model length above the body. Because the NPARC code can apply boundary conditions on internal portions of the grid, the grid generation modeled the entire domain in a single grid block. The grid for this case contained 35391 grid points.

Results. - Three solutions were obtained for this geometry to investigate the effect of turbulence model selection. The Baldwin-Lomax, Baldwin-Barth, and Chien $k-\varepsilon$ turbulence models were run at an NPR of 2.9 and a freestream Mach number of 0.8. Table II summarizes the flow field conditions.

Mach number contours are shown in figure 10 . The contours indicate the nozzle is operating underexpanded. The flow expands outward from the nozzle lip and then undergoes a series of shocks in the nozzle plume. Contours on the nozzle afterbody show flow acceleration around the shoulder of the boattail and sharp deceleration on the aft portion of the boattail. The separated region can be seen as the very low Mach number flow on the last third of the boattail.

Figure 11 shows the pressure coefficient distribution along the nozzle boattail. Overall, agreement with the experimental data is very good for all three turbulence models. The pressure distribution from the Baldwin-Barth model agrees well up to the separated region $(x / L \sim 0.98)$, when the distribution becomes low compared with the data. This indicates a stronger recirculation than that in the experiment. Also, the BaldwinBarth model predicts separation upstream of the experiment as indicated by the flattened region of the pressure distribution. The Baldwin-Lomax model begins to diverge from the experimental data well before separation in the adverse pressure gradient region. The $\mathrm{k}-\varepsilon$ model prediction is almost identical to the Baldwin-Barth prediction up to the separated region. But in this region, the flattening of the pressure distribution is not evident and results in a pressure coefficient that is higher than that in the experiment. This indicates that this model predicts a weak or no separation here.

Velocity vectors in the separated region (fig. 12) of the boattail give more insight into the behavior of the flow predicted by each turbulence model. The Chien $k-\varepsilon$ model predicts a small, weak separated zone. The 
predicted location of the separation point is downstream of the other models, and the component of the velocity magnitude of the flow reversal is small. The velocity vectors from the Baldwin-Lomax model show that the boundary layer upstream of the separation has a larger displacement thickness than those predicted by the other models. This large displacement of the streamlines away from the body accounts for the discrepancy between the experiment and the calculation in the adverse pressure gradient region of the boattail. The separation location for Baldwin-Lomax is the farthest upstream of all the models. The one-equation BaldwinBarth model predicts the strongest recirculation of all the turbulence models. It is the only model that has sufficient recirculation to induce a flattening of the pressure distribution as seen in the experimental data.

Figure 13 shows the NPARC predictions of pitot pressures compared with data in the nozzle exhaust plume at two locations downstream of the nozzle exit. This comparison shows that all the turbulence models similarly underpredict the jet spreading rate. However, data in the nozzle plume were taken very close to the nozzle exit plane. Obtaining more extensive data in the downstream portion of the plume would provide a more detailed analysis of the code's performance.

\section{Case 3: Two-Dimensional Nozzle}

Nozzle Description.- Several nozzle concepts that are currently being considered for application to the High Speed Civil Transport are two-dimensional (rectangular). Because the flow fields of axisymmetric and two-dimensional nozzles may differ significantly, a two-dimensional geometry was considered for code validation purposes. This geometry, also part of the AGARD study, was designated B4 and was tested at NASA Langley's 16-Foot Transonic Wind Tunnel (refs. 12 and 13). Figure 14 shows a three-dimensional view of the nozzle. The nozzle was installed on a generic two-dimensional forebody with a rounded ogive nose cone that transitions into a straight rectangular afterbody section. The assembly was then mounted in the tunnel on a sting-strut assembly as was the axisymmetric nozzle. The boattail angles of the sidewall and the flap were $6.93^{\circ}$ and $17.56^{\circ}$, respectively. The internal nozzle expanded only in the vertical plane (i.e., no expansion on the sidewalls) and had an area ratio of $A_{9} / A_{8}=1.25$. Static pressure data in the nozzle and on the boattail flaps and sidewalls were taken.

Although the accepted terminology describes this nozzle as two-dimensional, the nozzle's flow field is highly three-dimensional. A full three-dimensional Navier-Stokes analysis was required for this geometry.

Computational Grid.-The grid for this case was also provided by the McDonnell Douglas Aircraft Company, but was modi-fied for use with the NPARC code by adding an additional grid plane at each block interface to create grid overlap. The grid modeled the entire forebody, nozzle afterbody, internal nozzle, and plenum (fig. 15). The support strut and sting were not modeled. The nozzle was symmetric about both the horizontal and vertical axes. Symmetry about the vertical axis was used to reduce the computational domain to half its size. Although the symmetry about the horizontal axis could have been used to further reduce the domain, this was not done. By modeling both the upper and lower halves of the geometry, future studies at angle of attack can be readily performed on the same grid. The upstream and downstream grid boundaries were placed approximately 15 body lengths from the geometry; upper and lower boundaries were placed 5 body lengths from the model surface. Figures $15(\mathrm{e})$ and (f) give a detailed view of the grid around the nozzle afterbody and internal nozzle. The grid is constructed in seven blocks: an upstream section including the model's nose; a section containing the center portion of the model; a boattail section; a plenum section; an internal nozzle section; a small section that defines the base region at the nozzle exit plane; and a section downstream of the geometry to capture the exhaust plume (fig. 15(g)). The grid topology, an "H-grid" in the axial plane and a "C-grid" in the circumferential plane, is the same for all the blocks except the internal nozzle, which is an H-grid in all directions. The total number of grid points used is 831 105. Table I contains the dimensions of the individual grid blocks.

Results.- Two solutions were obtained for this geometry. Both the Baldwin-Barth and the Chien k- $\varepsilon$ turbulence models were run to assess effectiveness on the flow field. The Baldwin-Lomax model was not considered because of the complexity of the flow field. The external Mach number was 0.938 and the NPR was 4.017. Table II summarizes the flow field conditions.

Figure 11(a) shows Mach number contours along the xy-plane. The external flow expands to a supersonic Mach number around the boattail flap's shoulder and recompresses through a normal shock wave that stands just downstream of the expansion. The flow separates from the afterbody surface behind the shock and does not reattach on the surface. The internal nozzle contours indicate that the nozzle is operating close to its design pressure ratio. In the xz-plane (fig. 16(b)), the Mach number contours show a similar expansion and 
shock on the boattail's sidewall. But, because the sidewall angle is less than the flap angle, the flow remains attached to the surface.

Predicted pressure distributions along the internal nozzle surface compare very well with the experimental data (figs. 17(a) and (b)). Both turbulence models perform very well in flows with favorable pressure gradients such as this. Pressure distributions on the boattail flap (fig. 18(a)) indicate that the Baldwin-Barth model does a better job in predicting the shock location $(x / L=0.92)$ and the pressure coefficient in the separated zone ( $\mathrm{x} / \mathrm{L}=0.93$ to 1.00 ). However, both models perform very well considering the complexity of the flow field. Sidewall pressure distributions again show very good agreement (fig. 18(b)). Here the minimum pressure is underpredicted by both turbulence models. The Baldwin-Barth prediction is slightly more accurate in the recompressing region.

Velocity vectors on the boattail flap show two important differences between the solutions (fig. 19.). First, the Baldwin-Barth model predicts the onset of separation slightly upstream of the Chien k- $\varepsilon$ model. The location of the separation is closely coupled with the shock position that the Baldwin-Barth model predicted more accurately. Second, the Baldwin-Barth solution shows a stronger recirculation in the separated region. This stronger recirculation accounts for the lower pressure coefficient on the aft portion of the boattail.

\section{CONCLUSION}

The NPARC Reynolds-averaged Navier-Stokes code was validated for nozzle afterbody flow fields at transonic speeds. Three geometries were analyzed: an axisymmetric geometry with attached flow; an axisymmetric geometry with separated flow; and a two-dimensional nozzle with separated flow. The study investigated the code's ability to predict nozzle afterbody flows at several jet pressure ratios (on-design and offdesign), and the effect of turbulence model selection on results. Three turbulence models were evaluated: the algebraic Baldwin-Lomax model, the one-equation Baldwin-Barth model, and the two-equation Chien k- $\varepsilon$ model. The code showed excellent agreement for all geometries and turbulence models in the regions where the flow was attached. In the regions of flow separation, the accuracy of the predictions varied with each turbulence model. The Baldwin-Lomax model, which assumes a single-length scale, was not able to accurately predict complex separated flows. The Chien $k-\varepsilon$ model did a better job in the separated regions. However, this model underpredicted the size and location of the separated zone. The Baldwin-Barth model provided excellent agreement for both cases where the flow was separated. A limited comparison with data in the exhaust plume indicated that the NPARC code underpredicted the rate of jet spreading with all turbulence models.

\section{REFERENCES}

1. The NPARC Alliance: A User's Guide to NPARC. Nov., 1994.

2. AGARD Fluid Dynamics Panel: Aerodynamics of 3D Aircraft Afterbodies. AGARD AR-318, 1995.

3. Beam, R.; and Warming, R. F.: An Implicit Finite Difference Algorithm for Hyperbolic Systems in Conservation Law Form. J. Comp. Phys., vol. 22, no. 1, Sept. 1976, pp. 87-110.

4. Jameson, A.; Schmidt, W.; and Turkel, E.: Numerical Solutions of the Euler Equations by Finite Volume Method for Solving the Euler and Navier-Stokes Equations for High Speed Flows. AIAA Paper 81-1259, June 1981.

5. Baldwin, B.S.; and Lomax, H.: Thin Layer Approximation and Algebraic Model for Separated Turbulent Flows. AIAA Paper 78-257, Jan. 1978.

6. Baldwin, B.S.; and Barth, T.J.: A One-Equation Turbulence Transport Model for High Reynolds Number Wall-Bounded Flows. AIAA Paper 91-0610, Jan. 1991.

7. Chien, K.-Y.: Predictions of Channel and Boundary-Layer Flows With a Low-Reynolds-Number Turbulence Model. AIAA Journal, vol. 20, no. 1, Jan. 1982, pp. 33-38.

8. Henderson, W.P.; and Burley, J.R.: Effect of Empennage Arrangement on Single-Engine Nozzle/Afterbody Static Pressures at Transonic Speeds. NASA TP-2753, 1987.

9. Abeyounis, W.K.; and Putnam, L.E.: Investigation of the Flow Field Surrounding Circular-Arc Boattail Nozzles at Subsonic Speeds. NASA TP-1633, 1980.

10. Mason, M.L.; and Putnam, L.E.: Pitot Pressure Measurements in Flow Fields Behind Circular-Arc Nozzles with Exhaust Jets at Subsonic Free-Stream Mach Numbers. NASA TM-80169, 1979. 
11. Soni, B.K.: Two- and Three-Dimensional Grid Generation for Internal Flow Applications of Computational Fluid Dynamics. AIAA Paper 85-1526, July 1985.

12. Compton, W. B., et al.: Transonic Navier-Stokes Solutions of Three-Dimensional Afterbody Flows. NASA TM-4111, 1989.

13. Putnam, L. E.; and Mercer, C. E.: Pitot-Pressure Measurements in Flow Fields Behind a Rectangular Nozzle With Exhaust Jet for Free-Stream Mach Numbers of 0.00, 0.60 and 1.20. NASA TM-88990, 1986.

TABLE I-COMPUTATIONAL GRID DIMENSIONS

\begin{tabular}{|c|c|c|c|c|c|}
\hline & Case & Blocks & $\begin{array}{l}\text { Section } \\
\text { description }\end{array}$ & $\begin{array}{l}\text { Dimensions, } \\
\text { grid points }\end{array}$ & $\begin{array}{l}\text { Total grid } \\
\text { size }\end{array}$ \\
\hline \multirow{4}{*}{$\begin{array}{l}\text { Axisymmetric; } \\
\text { attached flow }\end{array}$} & \multirow{4}{*}{1} & \multirow{4}{*}{4} & Upstream & 39 by 45 & \multirow{4}{*}{11647} \\
\hline & & & Boattail & 61 by 45 & \\
\hline & & & Nozzle & 54 by 45 & \\
\hline & & & Downstream & 53 by 89 & \\
\hline $\begin{array}{l}\text { Axisymmetric; } \\
\text { separated flow }\end{array}$ & 2 & 1 & All & 251 by 141 & 35391 \\
\hline \multirow{7}{*}{ Two-dimensional } & \multirow{7}{*}{3} & \multirow{7}{*}{7} & Upstream & 43 by 41 by 33 & \multirow{7}{*}{831105} \\
\hline & & & Forebody & 29 by 41 by 61 & \\
\hline & & & Boattail & 50 by 49 by 101 & \\
\hline & & & Plenum & 16 by 33 by 89 & \\
\hline & & & Nozzle & 48 by 41 by 65 & \\
\hline & & & Base & 21 by 91 by 101 & \\
\hline & & & Downstream & 34 by 41 by 61 & \\
\hline
\end{tabular}

TABLE II.-FLOW CONDITIONS

\begin{tabular}{|c|c|c|c|c|c|c|}
\hline & Case & $\begin{array}{c}\text { Freestream } \\
\text { Mach number, } \\
\mathrm{M}_{\infty}\end{array}$ & $\begin{array}{c}\text { Freestream } \\
\text { dynamic pressure, } \\
\mathrm{q}_{\infty}, \mathrm{psi}\end{array}$ & $\begin{array}{c}\text { Freestream } \\
\text { stagnation } \\
\text { temperature, } \\
{ }^{\mathrm{R}} \mathrm{R}\end{array}$ & $\begin{array}{c}\text { Jet stagnation } \\
\text { temperature, } \\
{ }^{\circ} \mathrm{R}\end{array}$ & $\begin{array}{c}\text { Nozzle pressure } \\
\text { ratio, } \\
\text { NPR }=\mathrm{p}_{\mathrm{o}} / \mathrm{p}_{\infty}\end{array}$ \\
\hline $\begin{array}{c}\text { Axisymmetric; } \\
\text { attached flow }\end{array}$ & 1 & 0.901 & 4.929 & 606.5 & 530.0 & $\begin{array}{l}2.033 \\
4.991\end{array}$ \\
\hline $\begin{array}{c}\text { Axisymmetric; } \\
\text { separated flow }\end{array}$ & 2 & 0.800 & 4.317 & 579.6 & 534.6 & 2.900 \\
\hline Two-dimensional & 3 & 0.938 & 5.130 & 619.3 & 549.9 & 4.017 \\
\hline
\end{tabular}




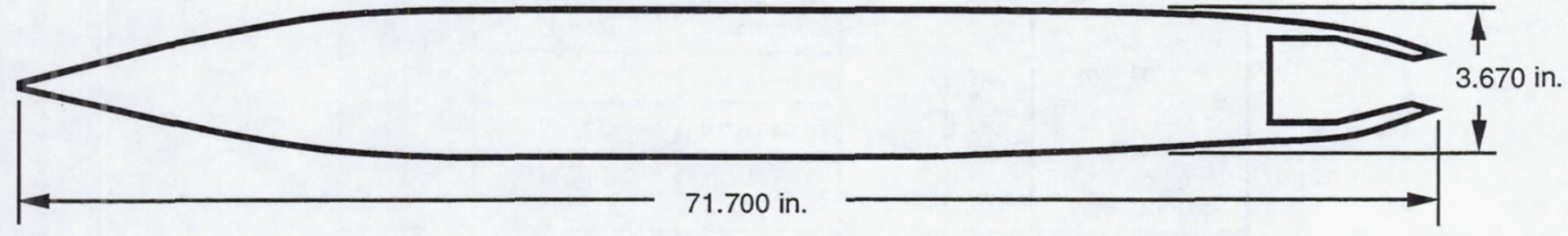

(a)

(b)

Figure 1.-Axisymmetric nozzle geometry (Case 1). (a) Nacelle. (b) Nozzle detail. 


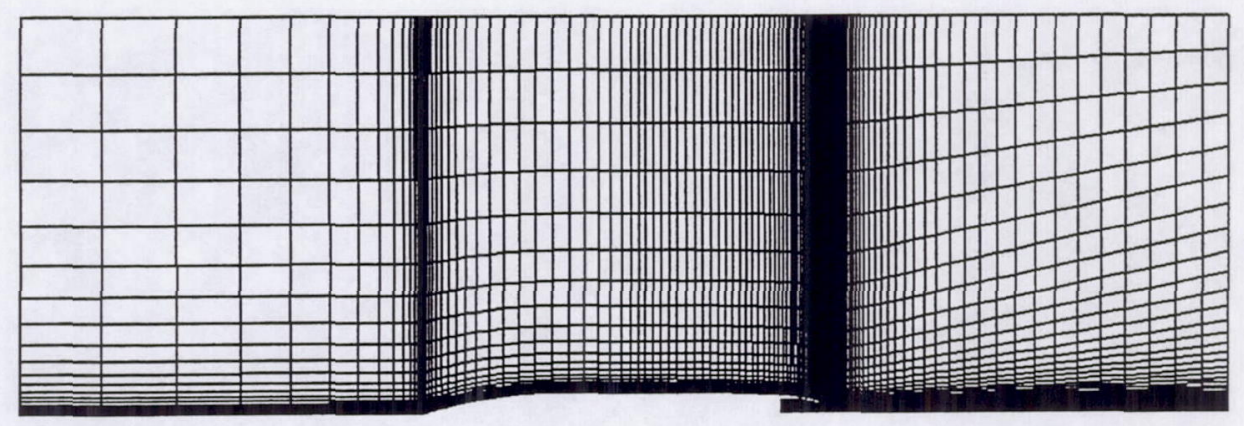

(a)

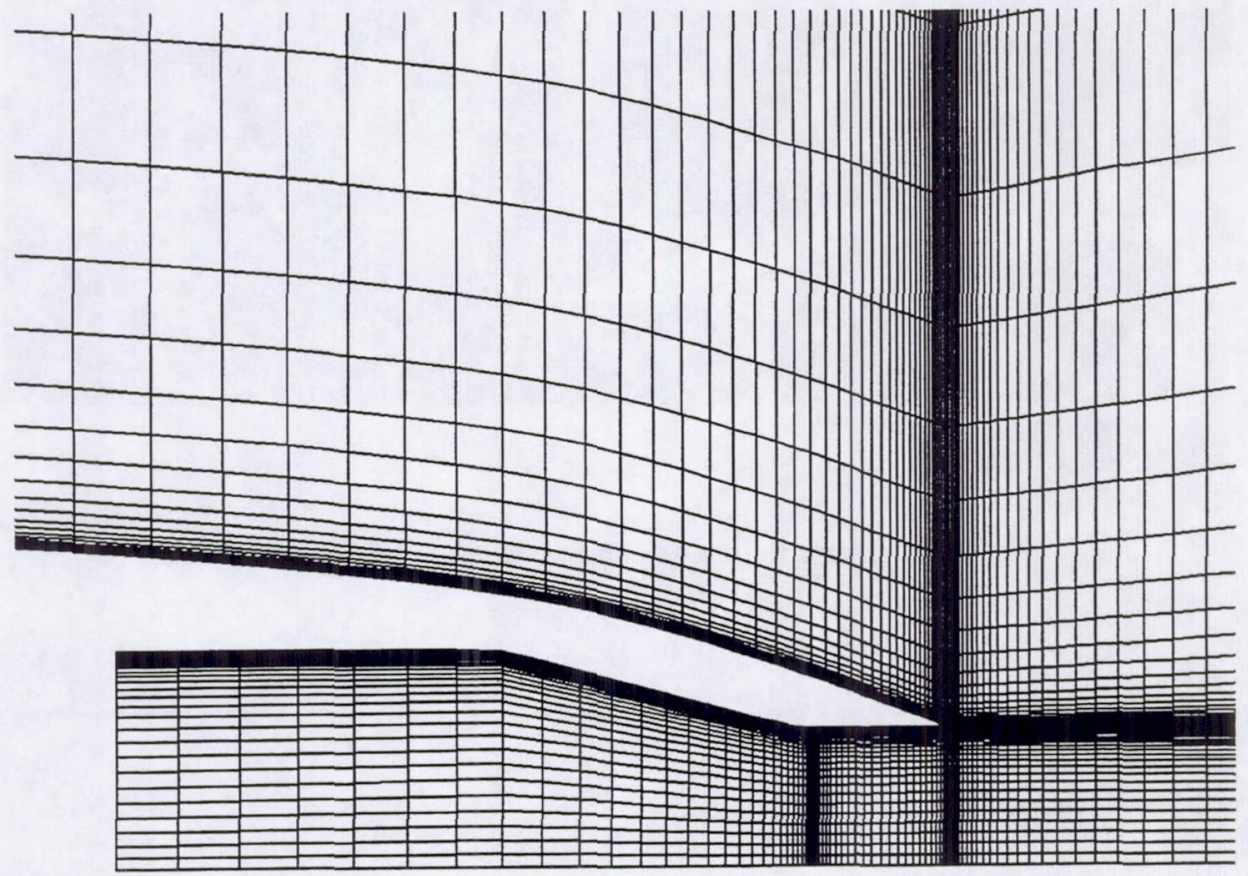

(b)
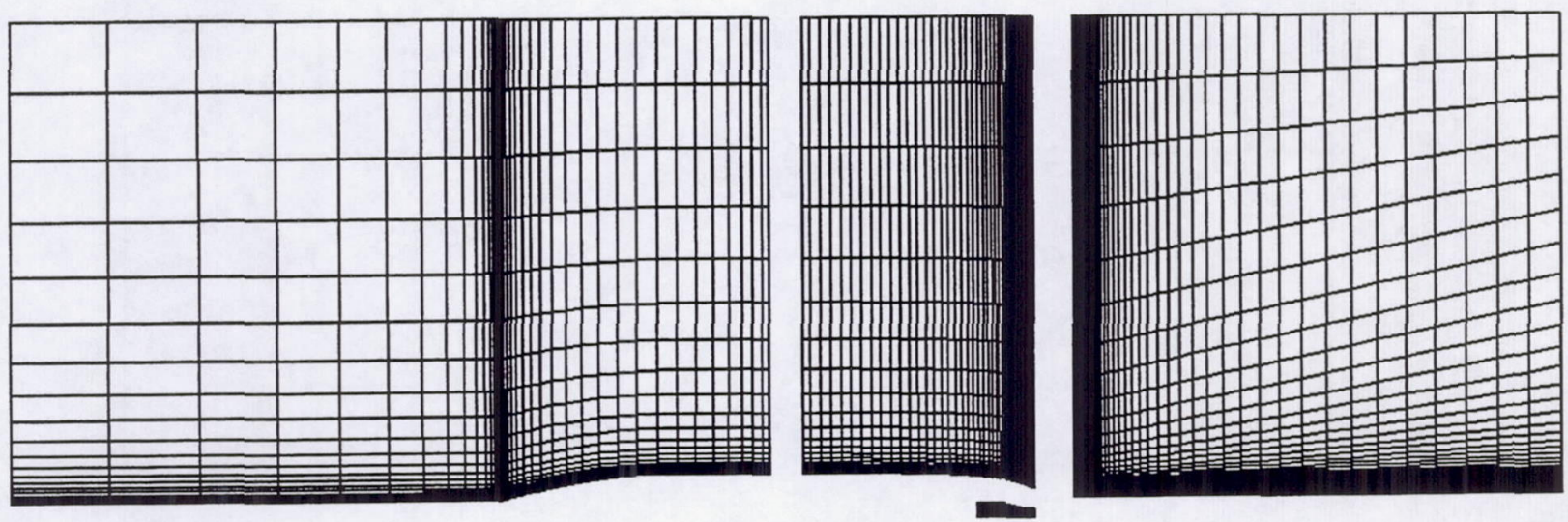

(c)

Figure 2.-Computational grid (Case 1). (a) Entire domain. (b) Nozzle detail. (c) Block structure. 


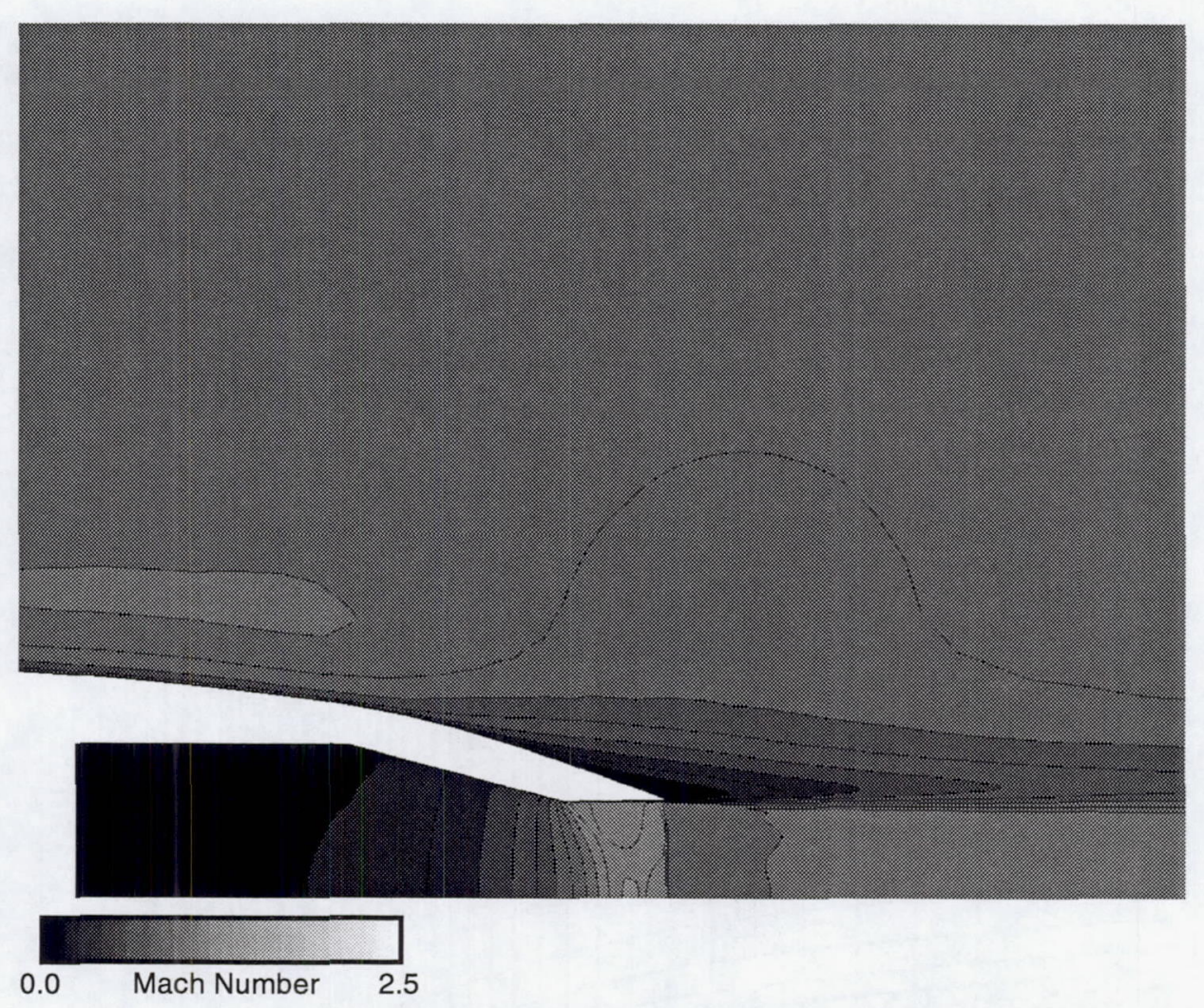

Figure 3.-Mach number contours (Case $1 ; \mathrm{NPR}=2.033$ ).

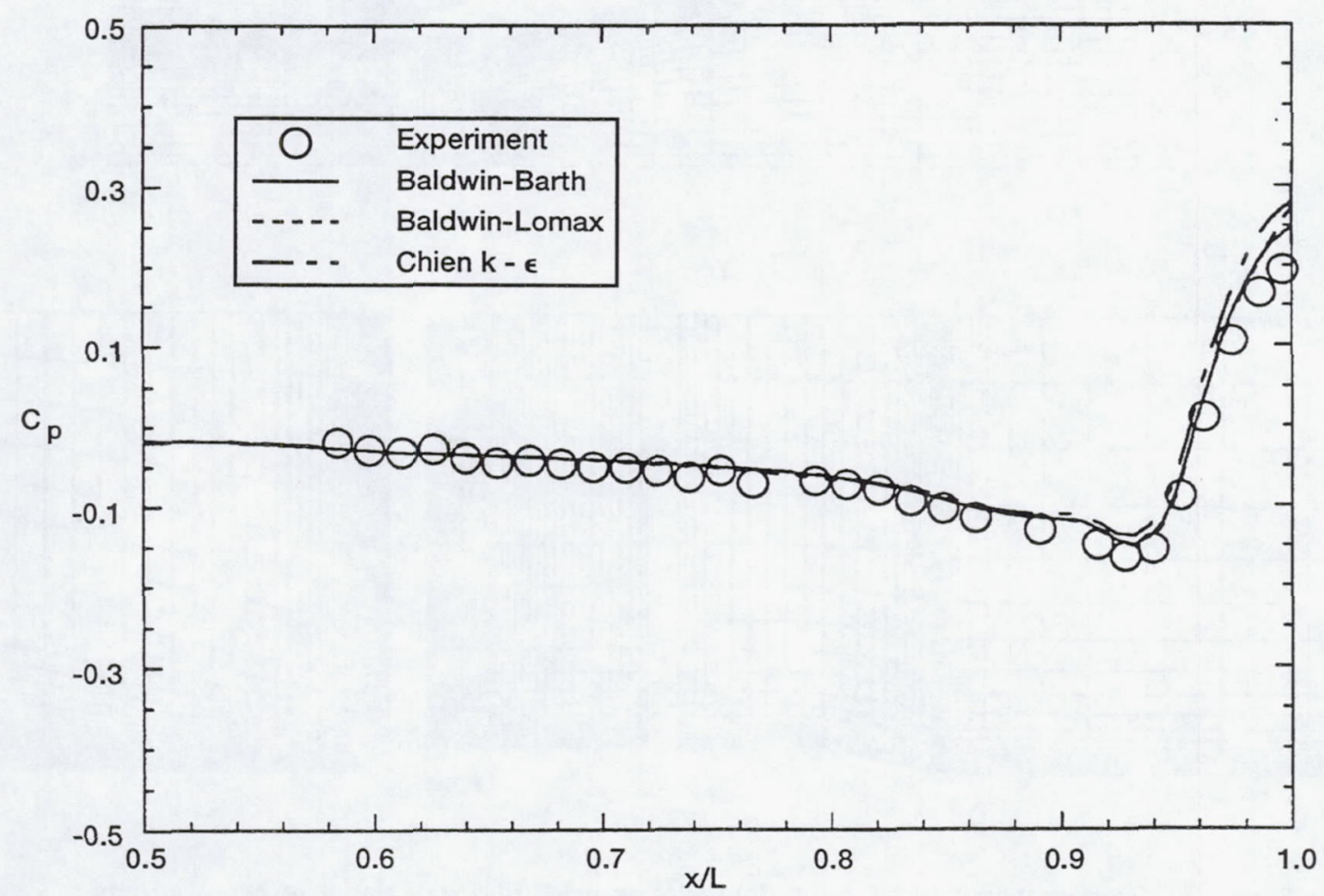

Figure 4.-External pressure distribution (Case 1; NPR $=2.033$ ). 


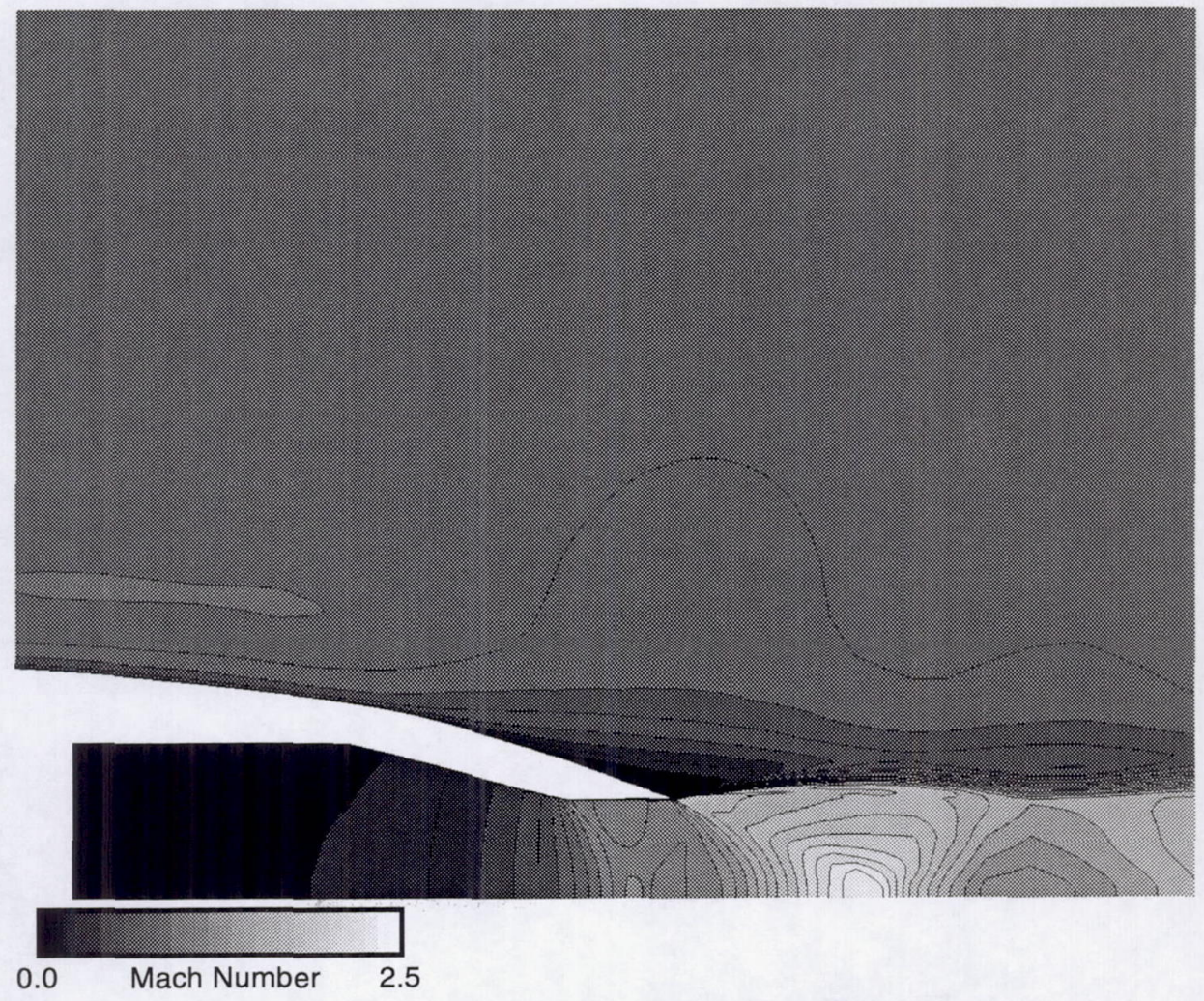

Figure 5.-Mach number contours (Case 1; NPR = 4.991).

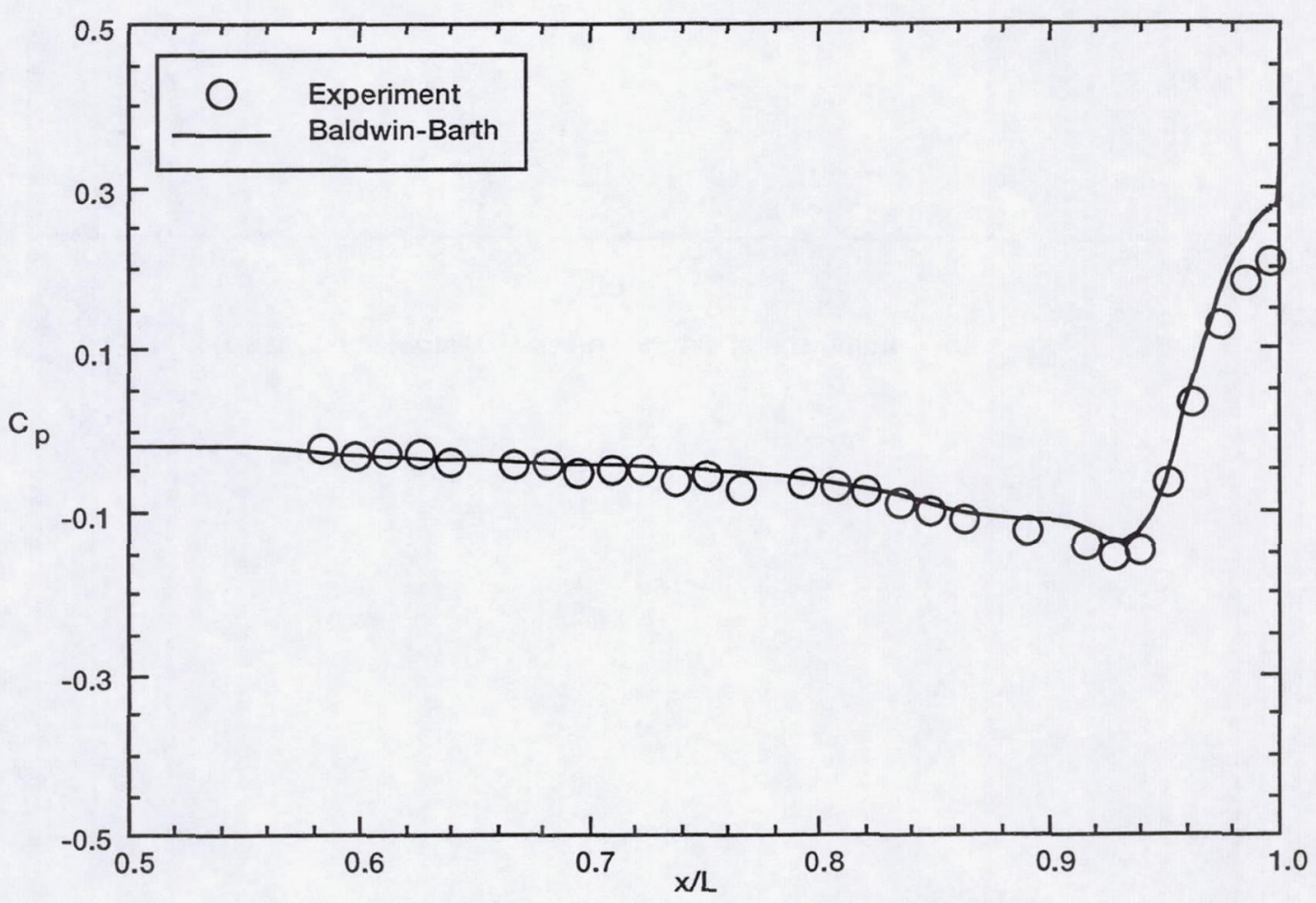

Figure 6.-External pressure distribution (Case 1; NPR = 4.991). 


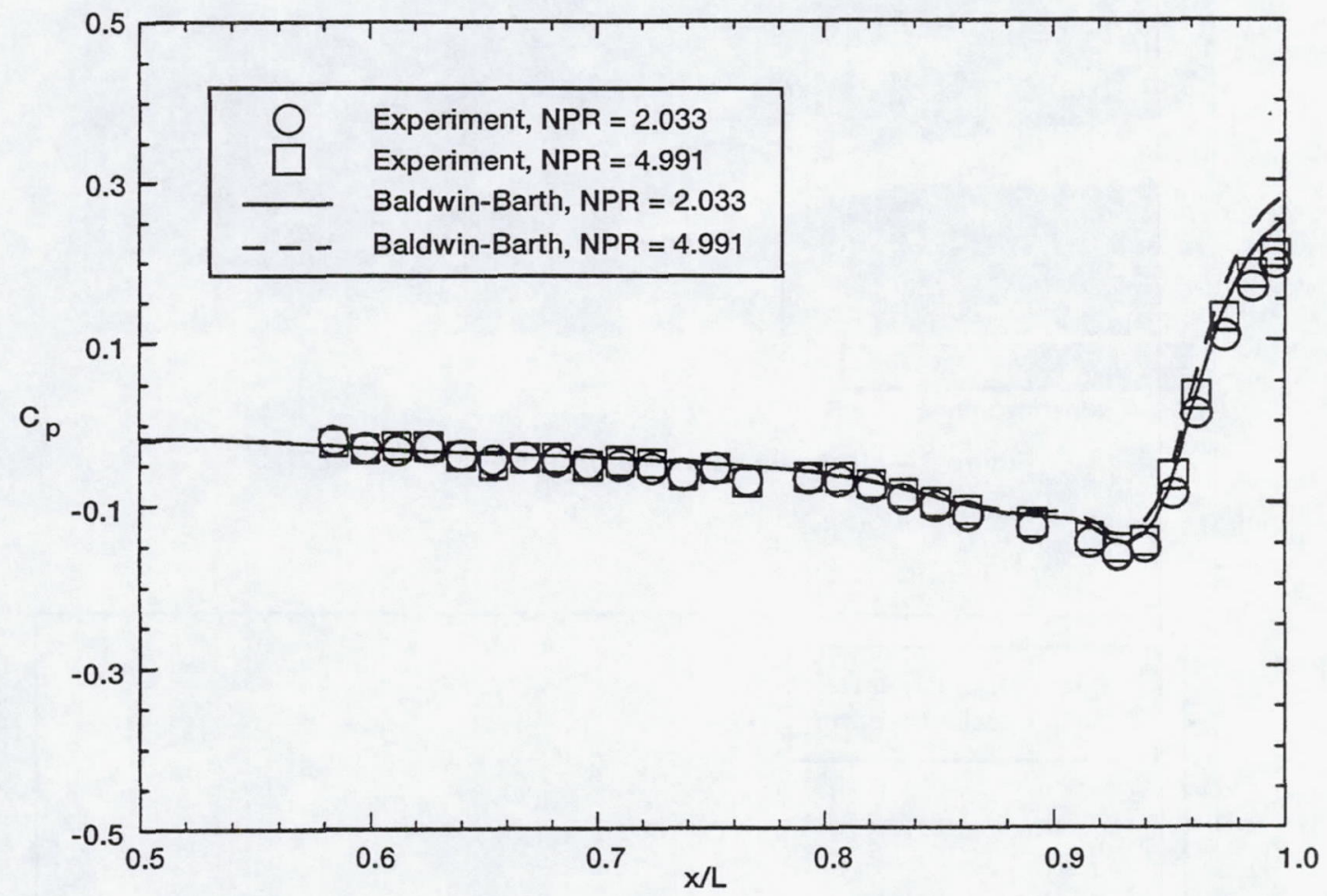

Figure 7.-Comparison of external pressure distribution (Case 1). 


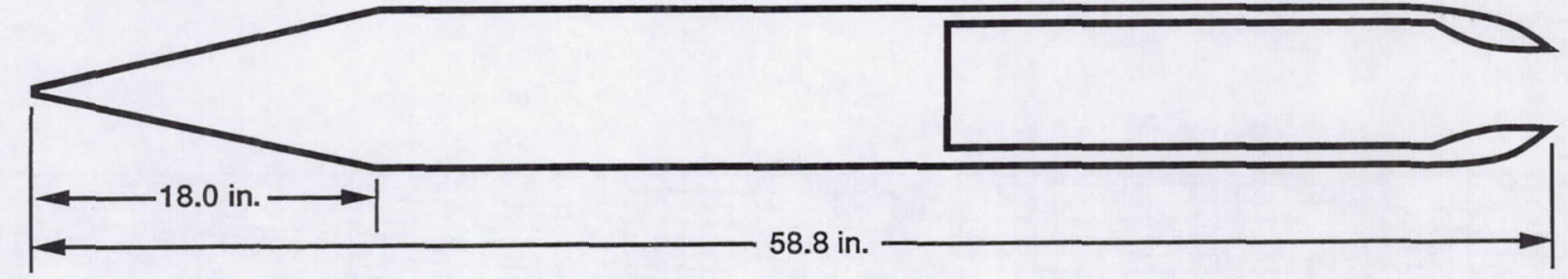

(a)

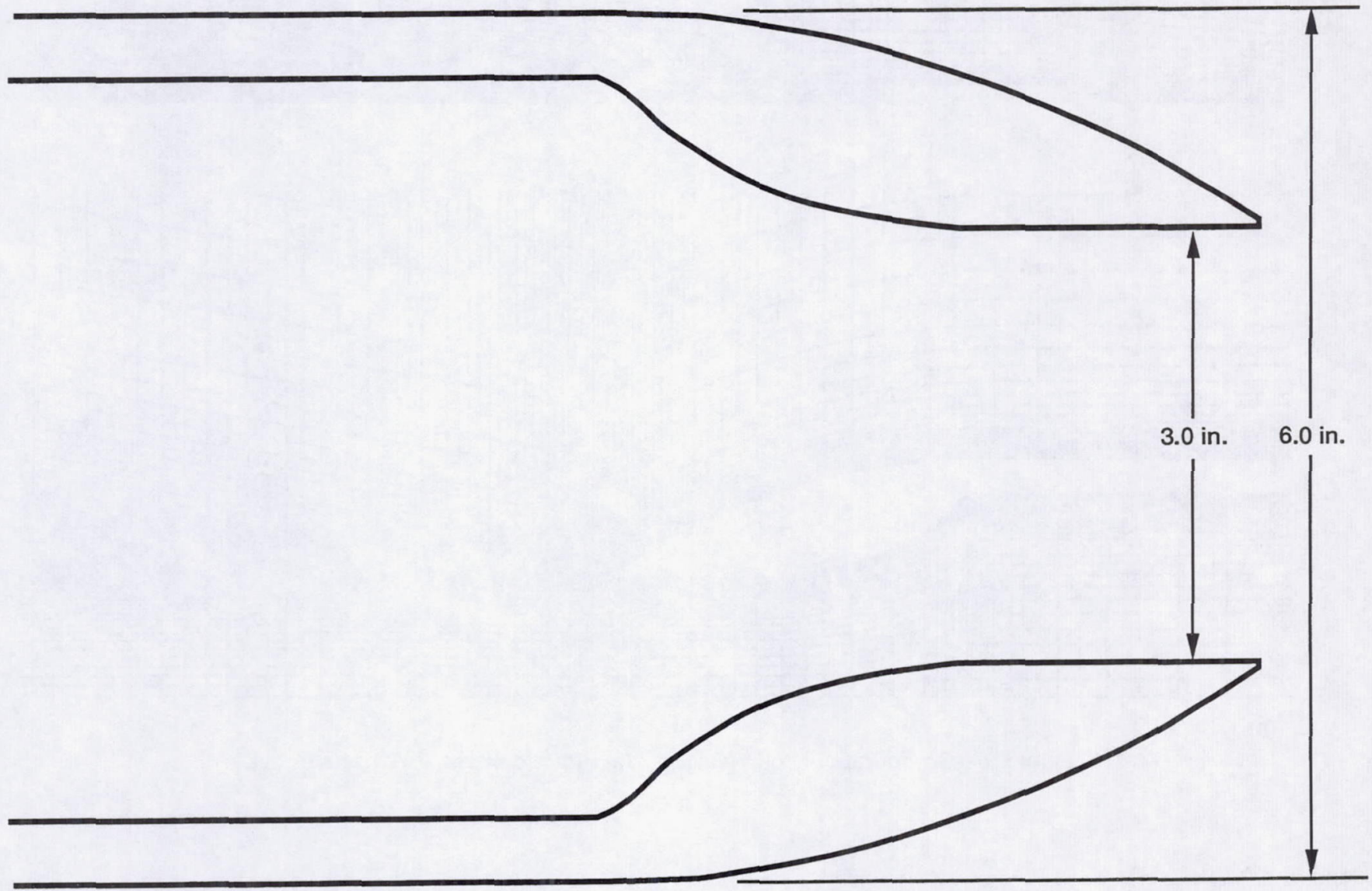

(b)

Figure 8.-Axisymmetric nozzle geometry (Case 2). (a) Nacelle. (b) Nozzle detail. 

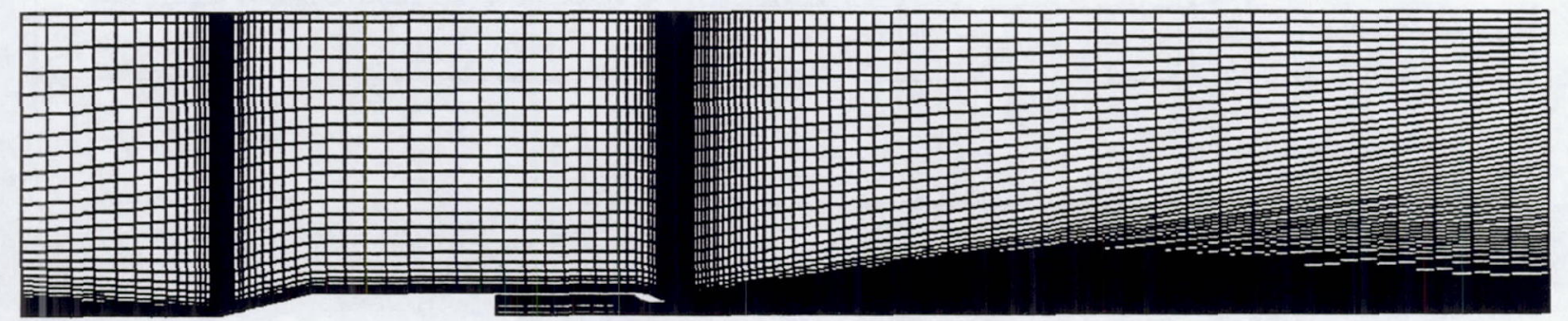

(a)

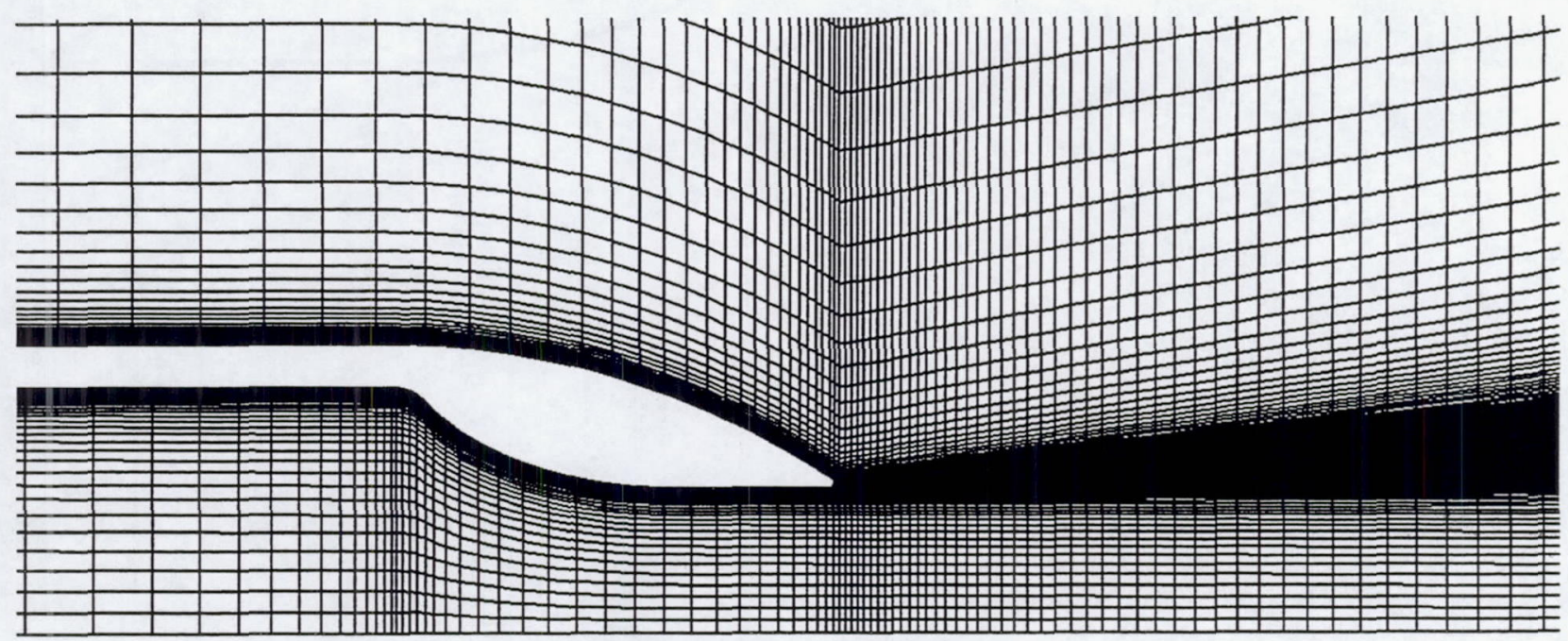

(b)

Figure 9.-Computational grid (Case 2). (a) Entire domain. (b) Nozzle detail. 


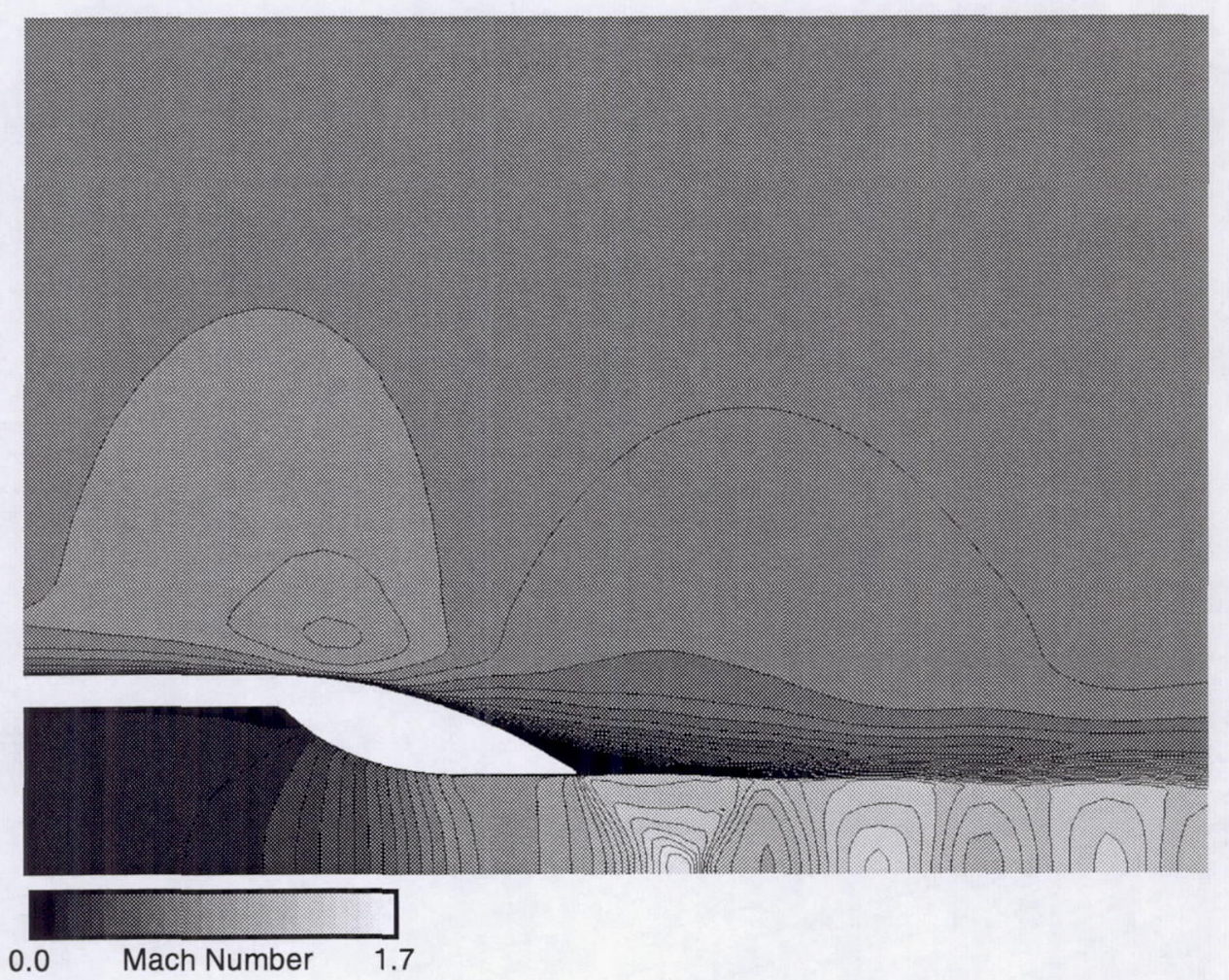

Figure 10.-Mach number contours (Case 2).

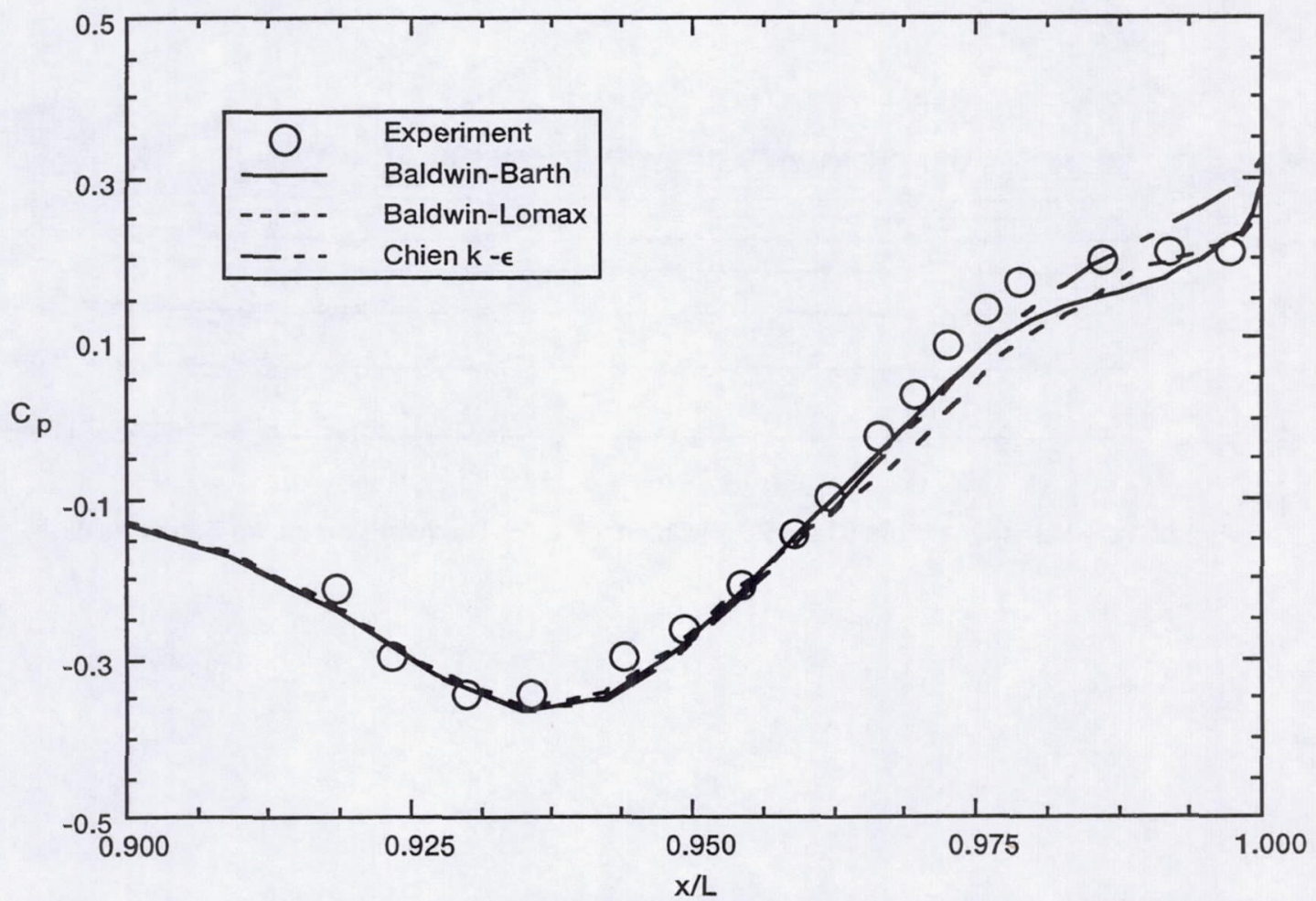

Figure 11.-External pressure distribution (Case 2). 


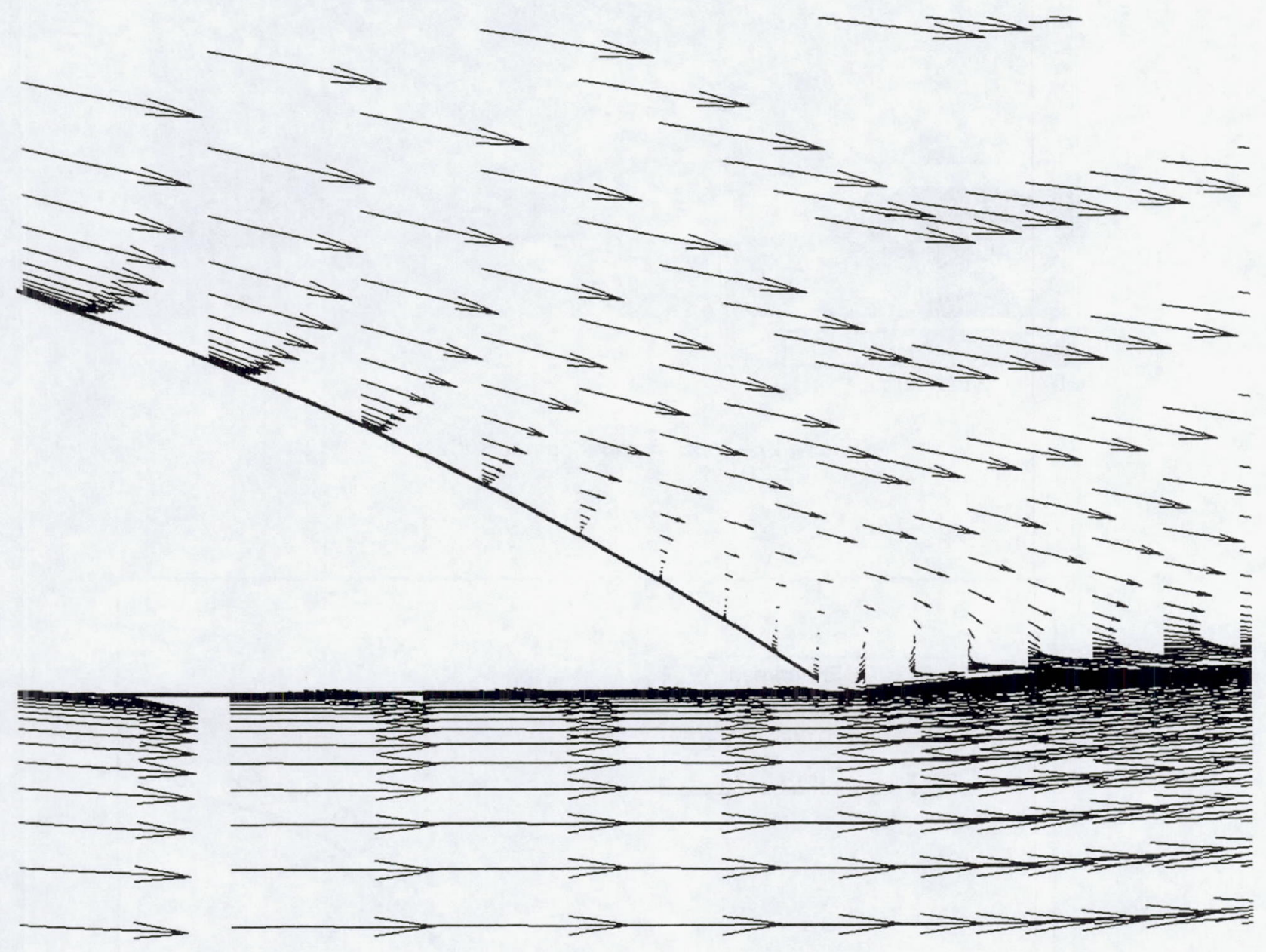

(a)

Figure 12.-Velocity vectors (Case 2). (a) Chien k - $\epsilon$. (b) Baldwin-Lomax. (c) Baldwin-Barth. 


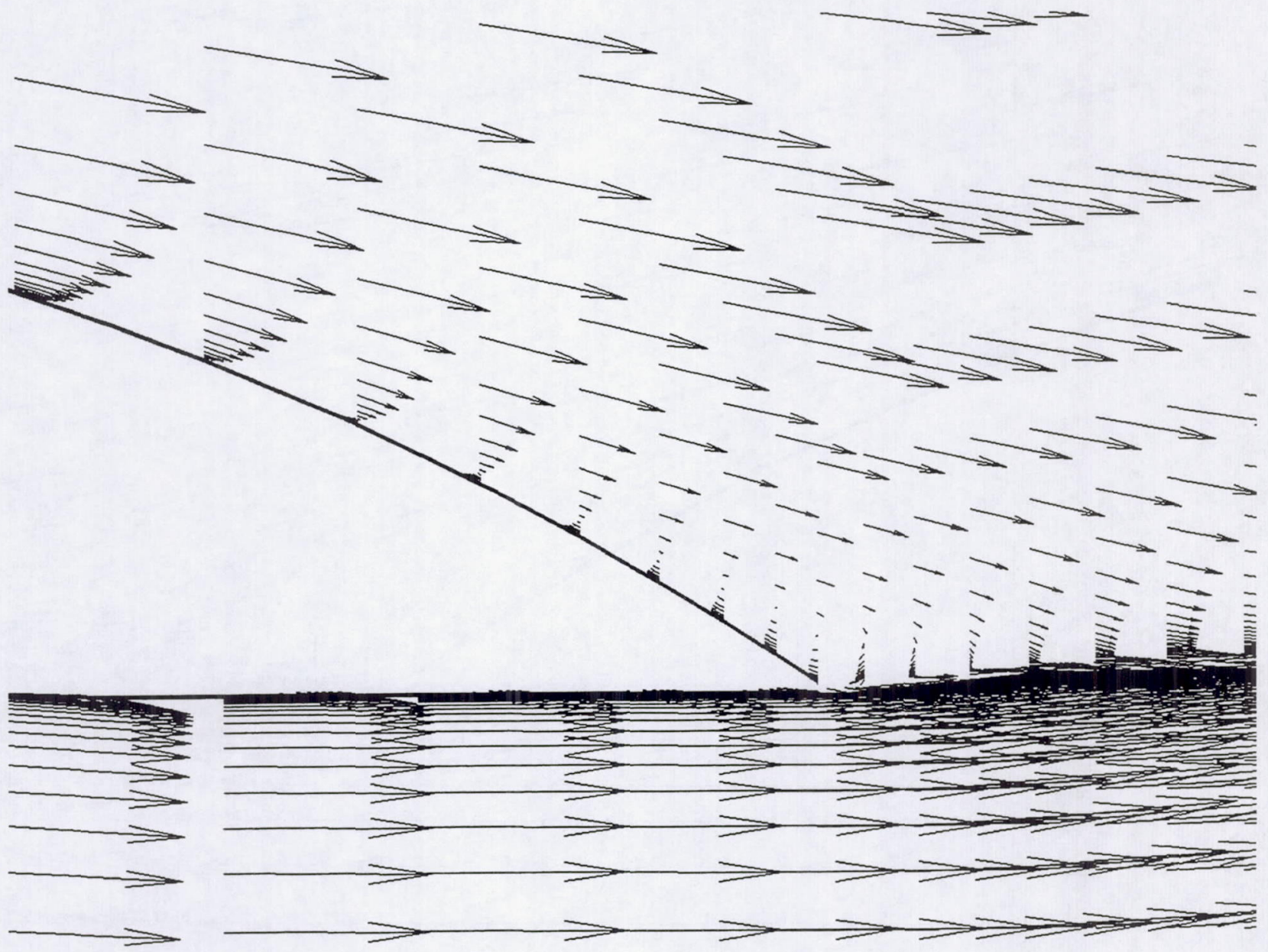

(b)

Figure 12.-Continued. (b) Baldwin-Lomax. 


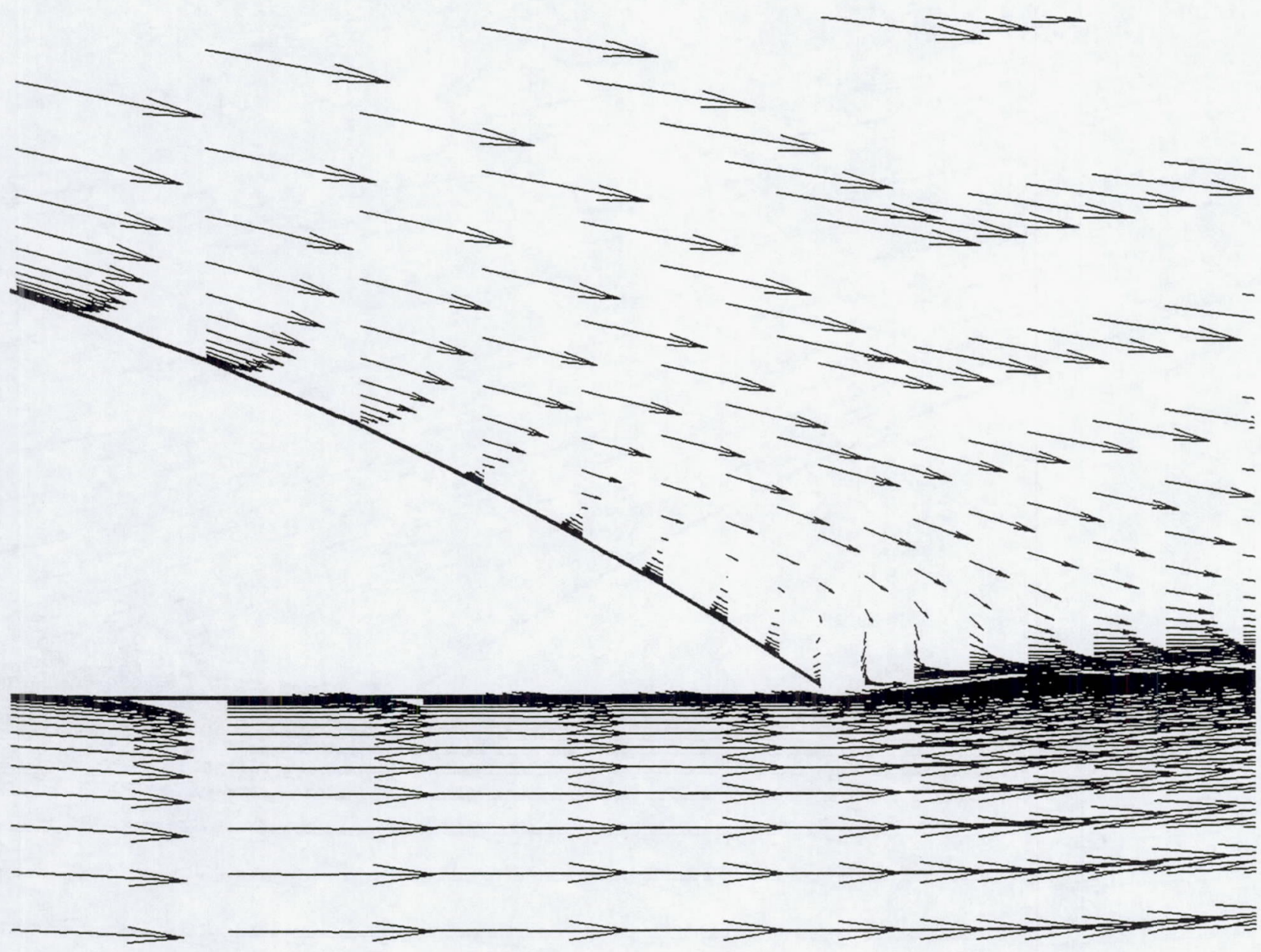

(c)

Figure 12.-Concluded. (c) Baldwin-Barth. 

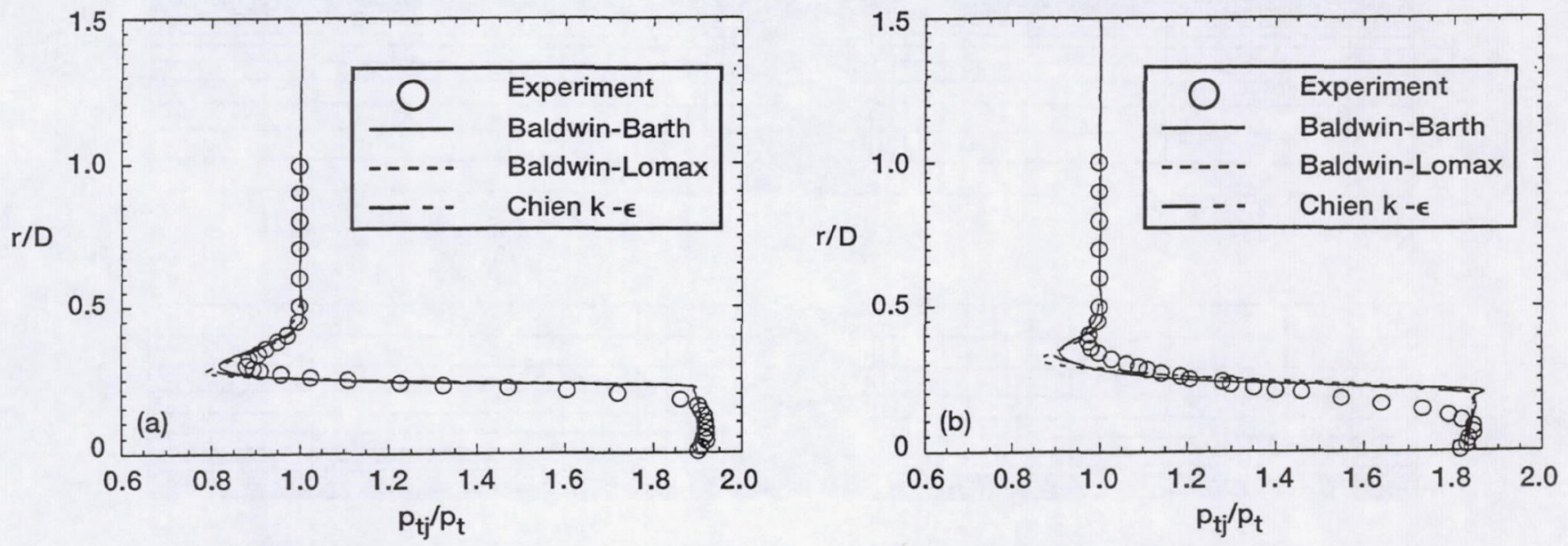

Figure 13.-Pitot pressure distributions in exhaust plume (Case 2). (a) $x / L=0.051$. (b) $x / L=0.310$.

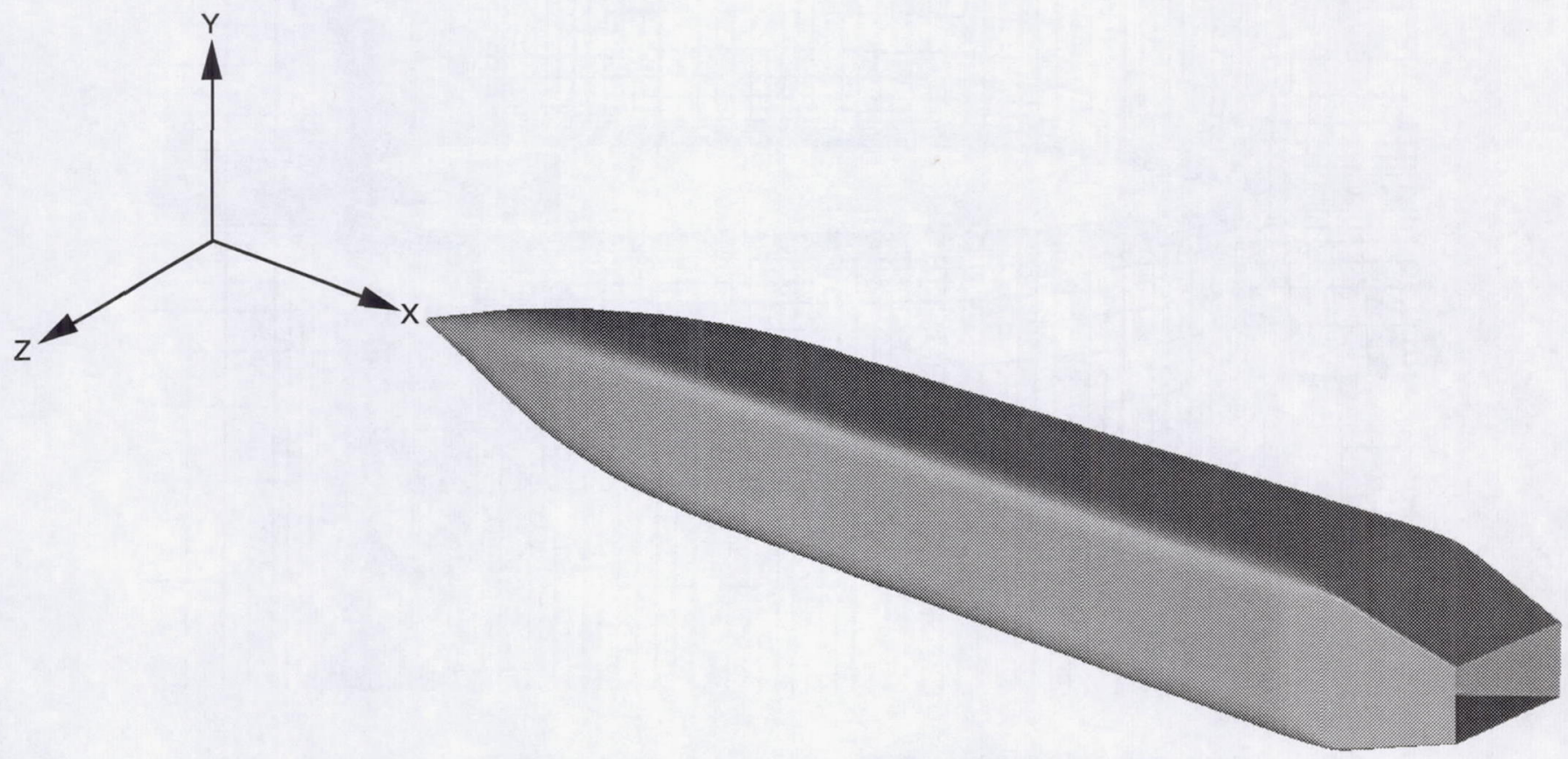

Figure 14.-Two-dimensional nozzle geometry (Case 3; three-dimensional view). 

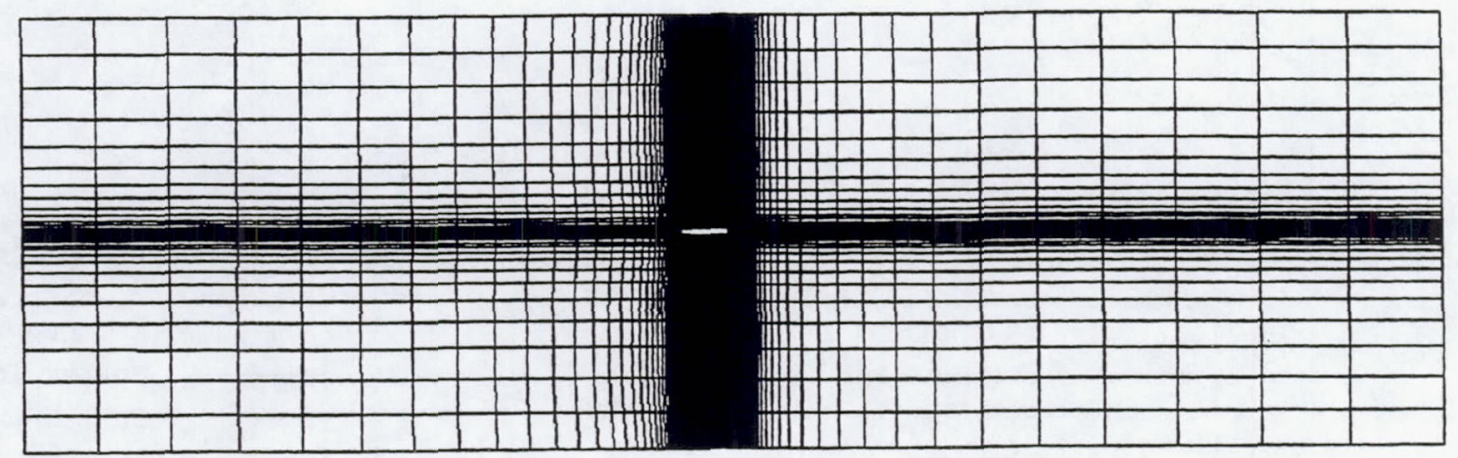

(a)
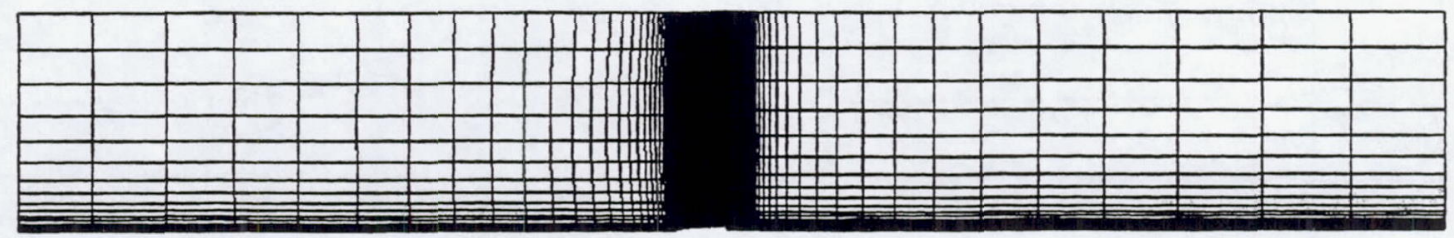

(b)

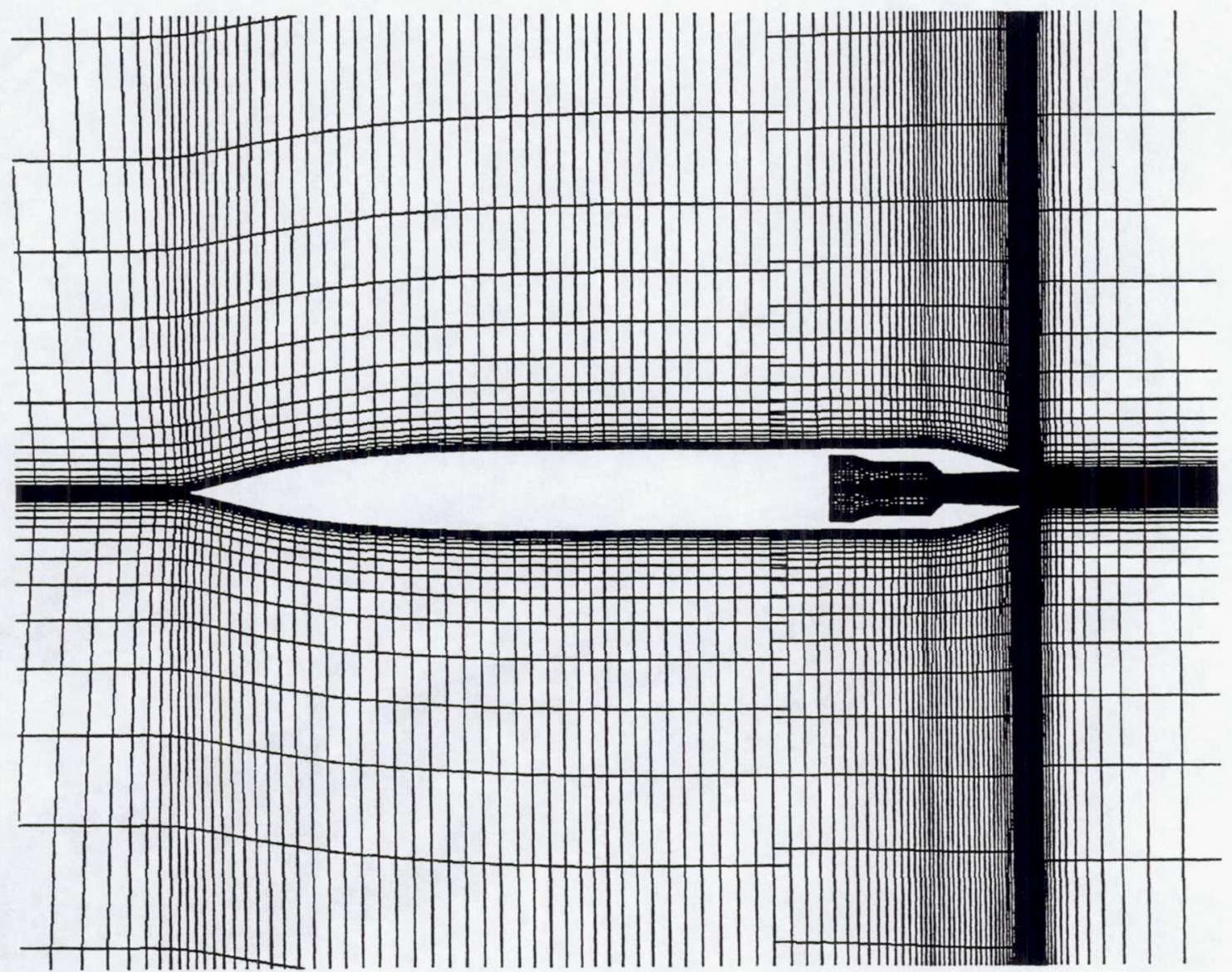

(c)

Figure 15.-Computational grid (Case 3). (a) Entire domain, $x y$-plane. (b) Entire domain, $x z$-plane. (c) Nacelle, xy-plane. (d) Nacelle, xz-plane. (e) Nozzle detail, xy-plane. (f) Nozzle detail, xz-plane. (g) Block structure. 


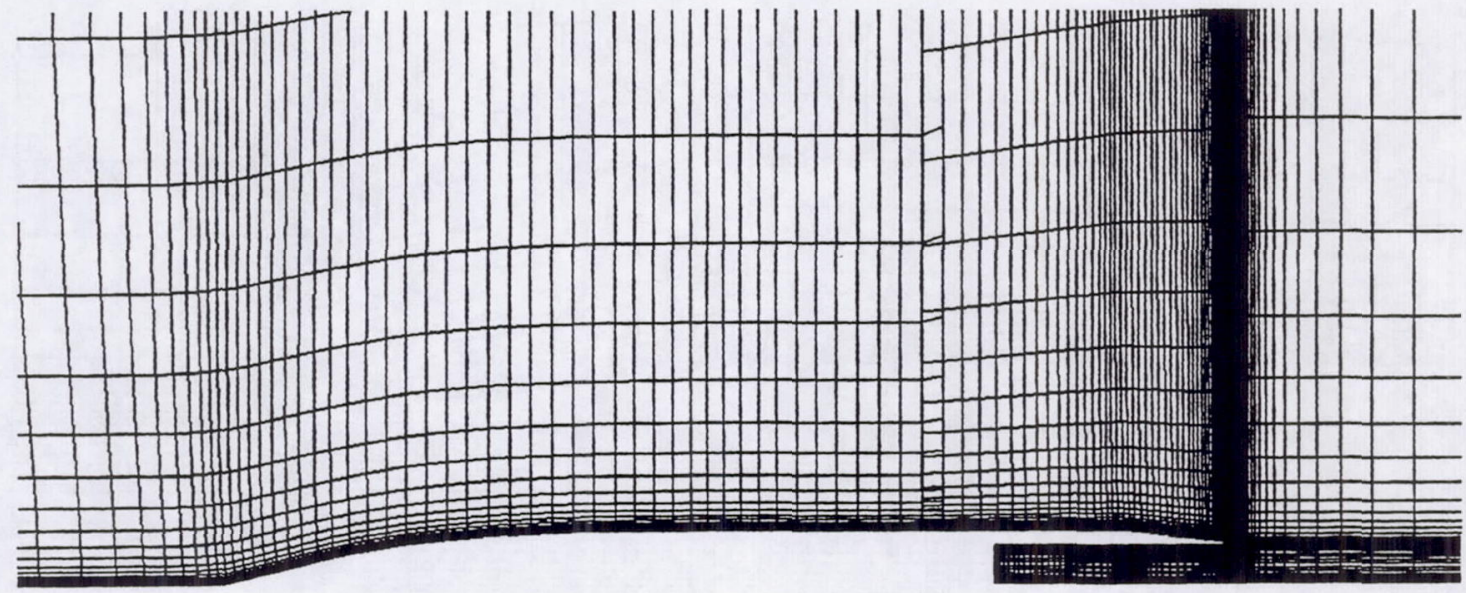

(d)

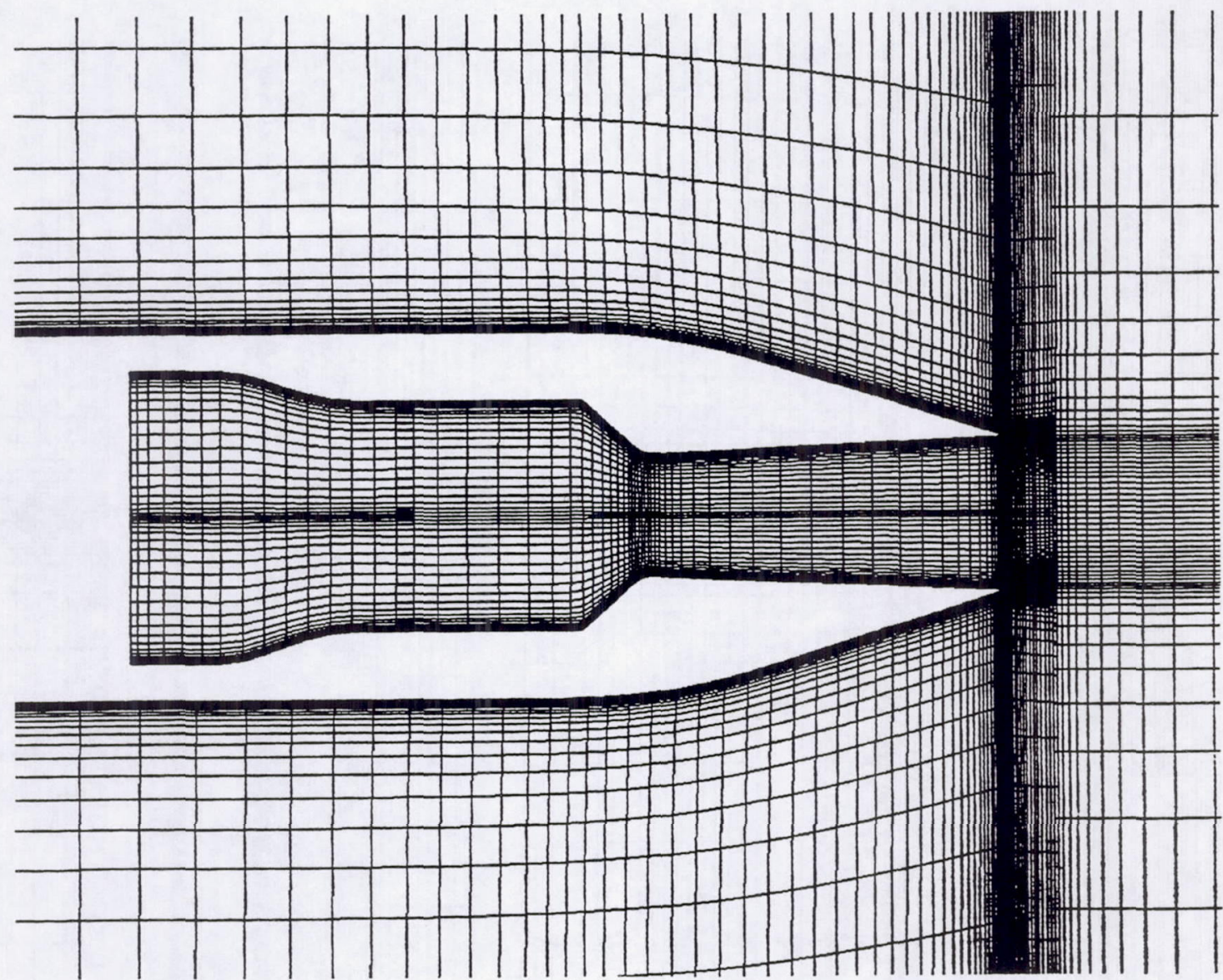

(e)

Figure 15.-Continued. (d) Nacelle, xz-plane. (e) Nozzle detail, xy-plane. 


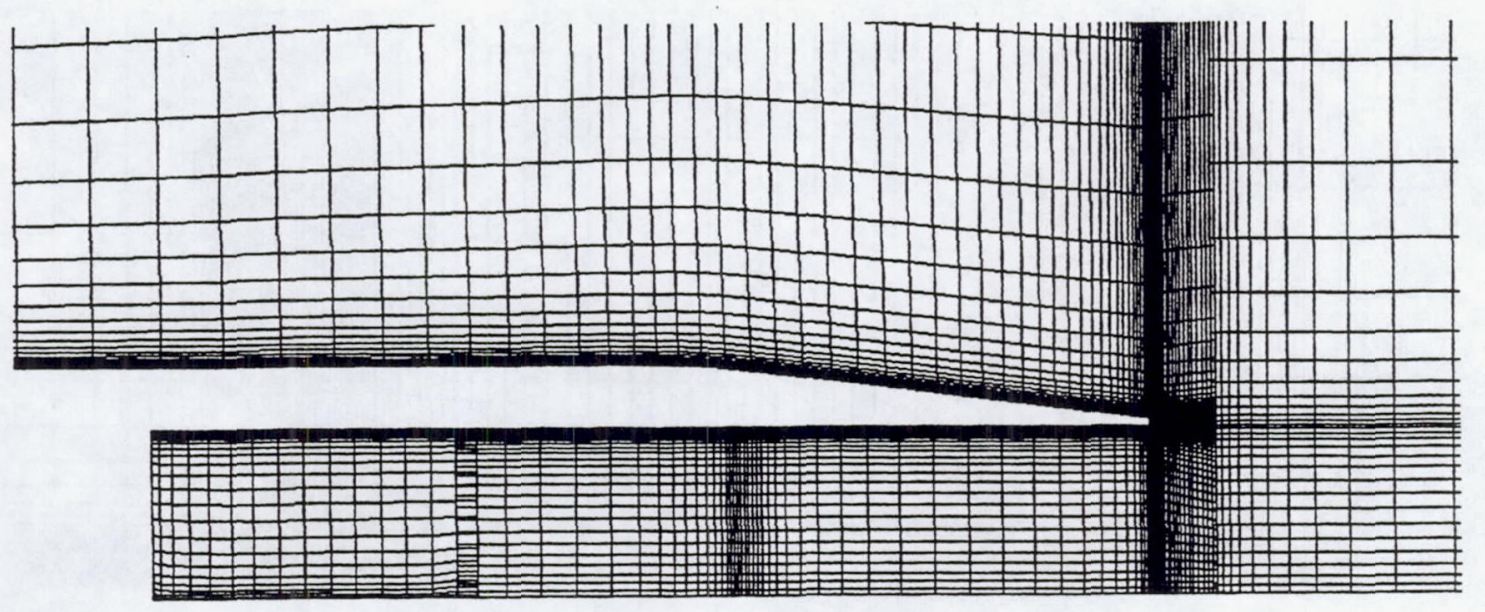

(f)
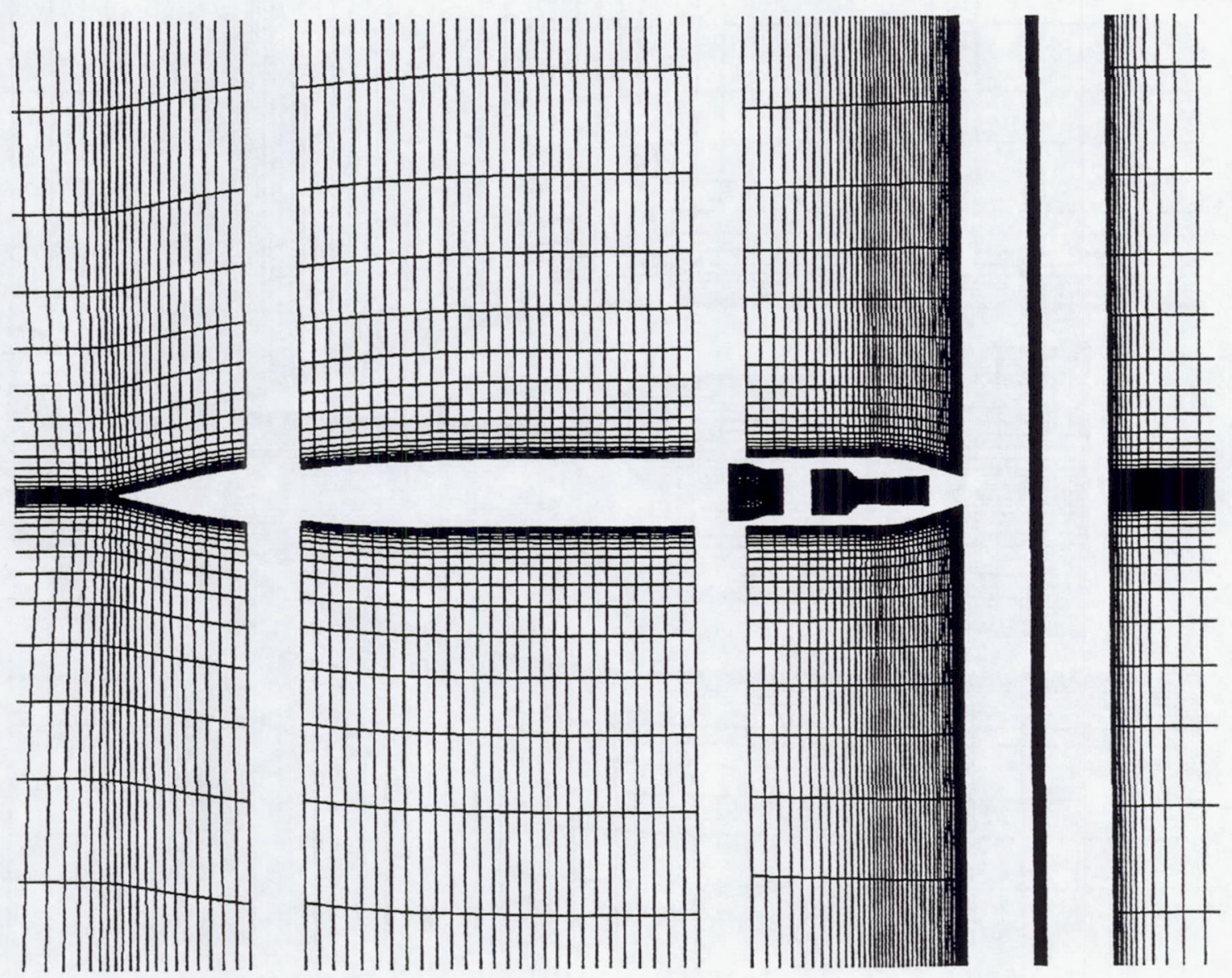

(g)

Figure 15.-Concluded. (f) Nozzle detail, xz-plane. (g) Block structure. 

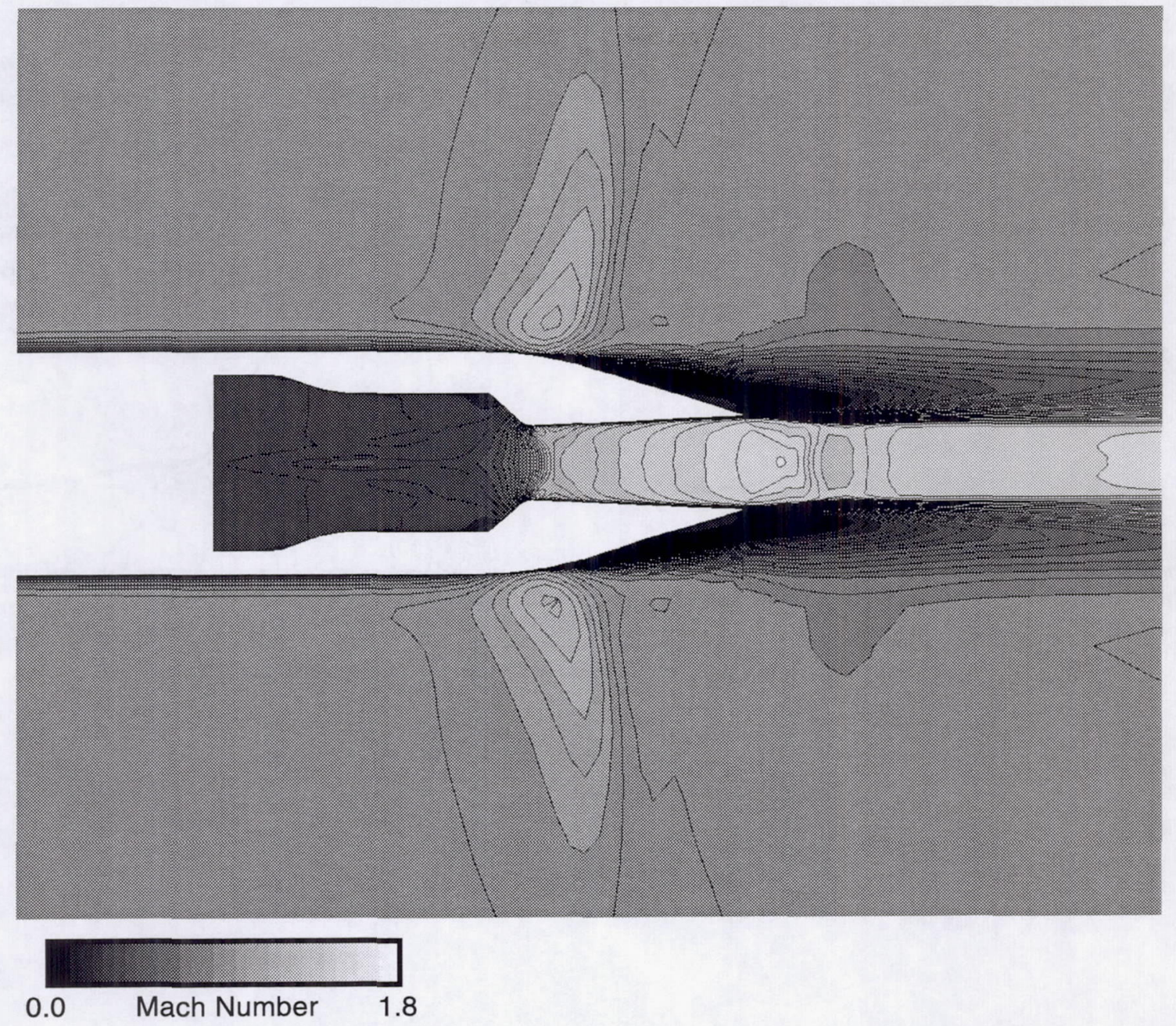

(a)
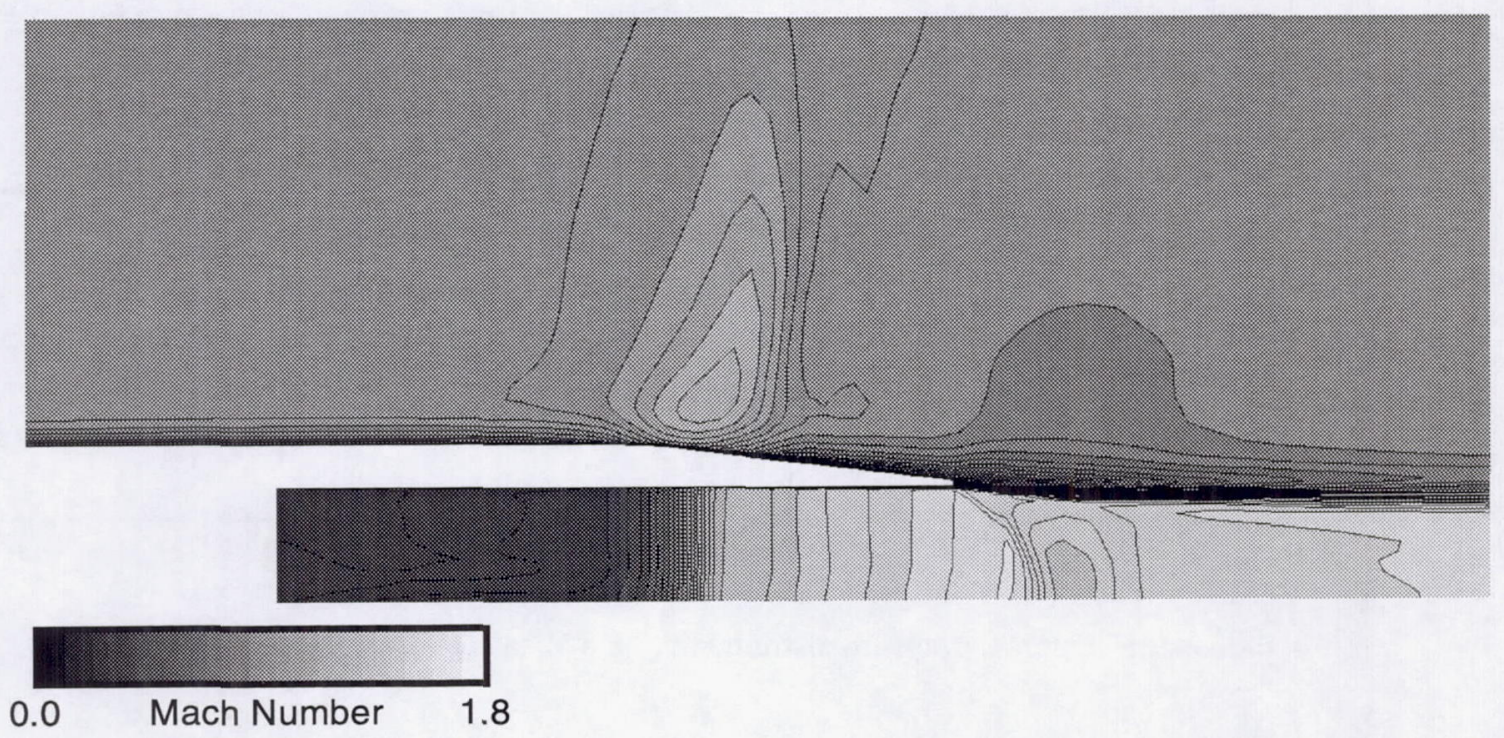

(b)

Figure 16.-Mach number contours (Case 3). (a) xy-plane. (b) xz-plane. 

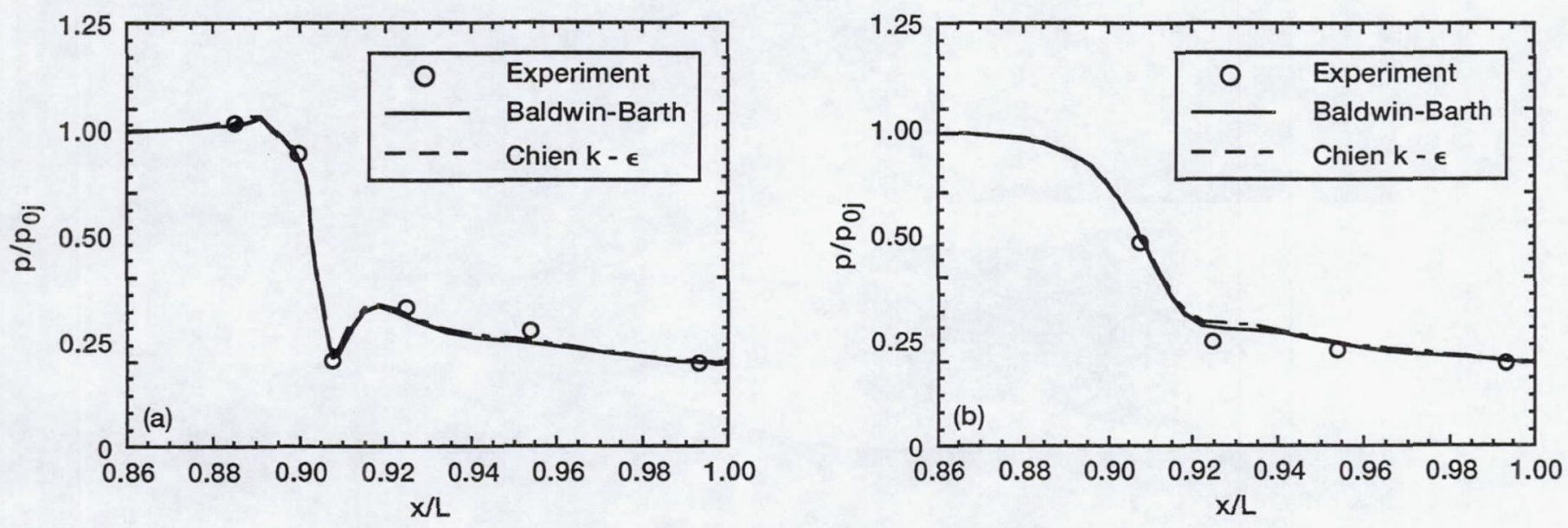

Figure 17.-Internal pressure distribution (Case 3). (a) xy-plane. (b) xz-plane.
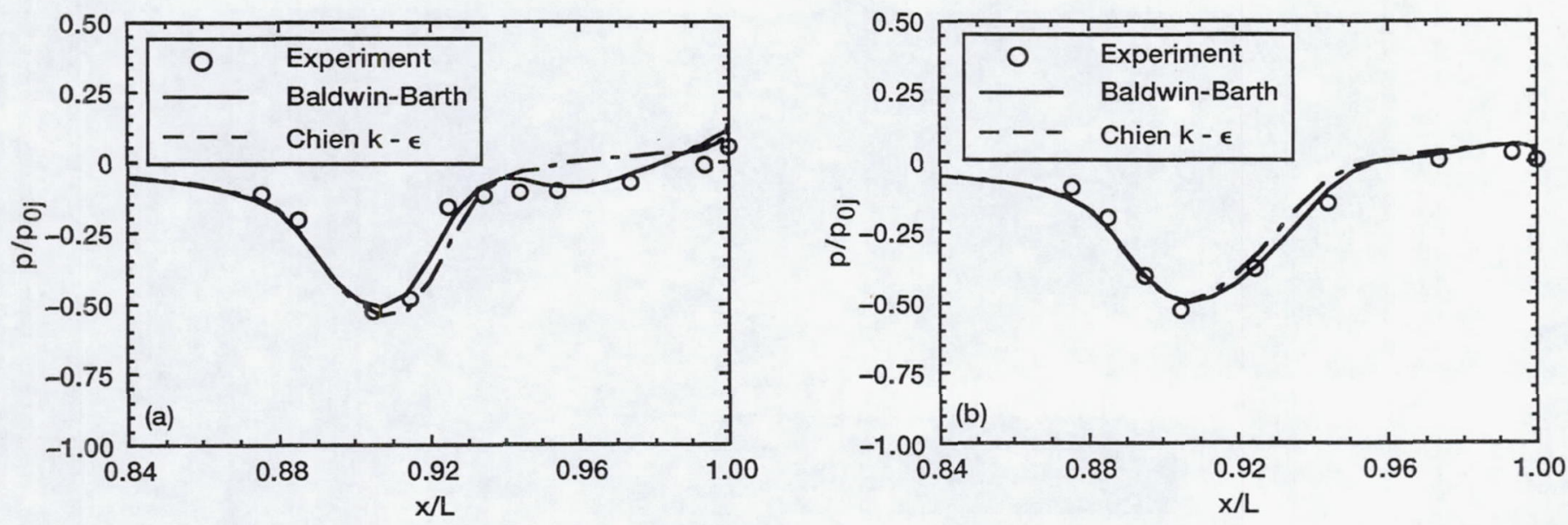

Figure 18.-External pressure distribution (Case 3). (a) xy-plane. (b) xz-plane. 


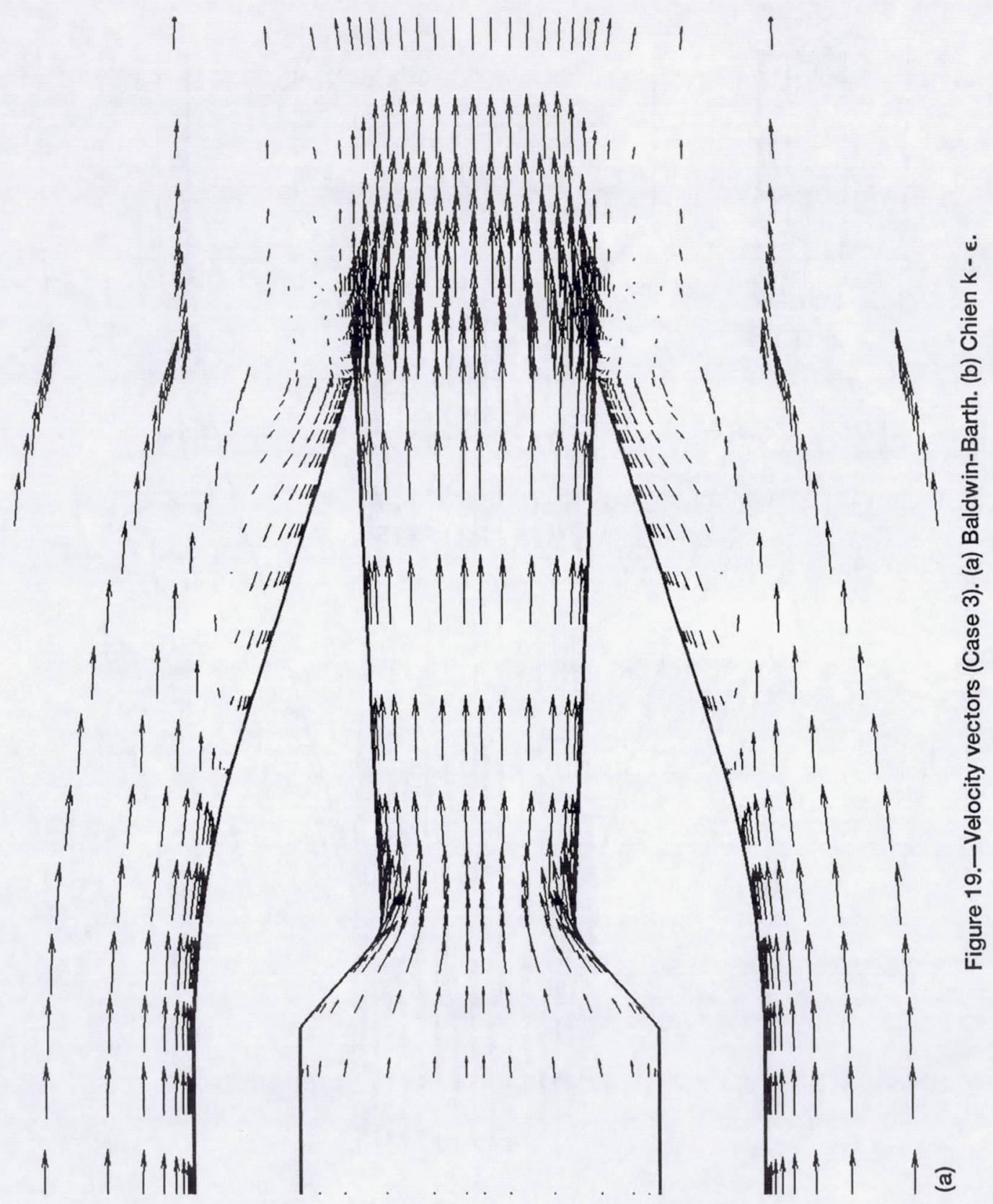




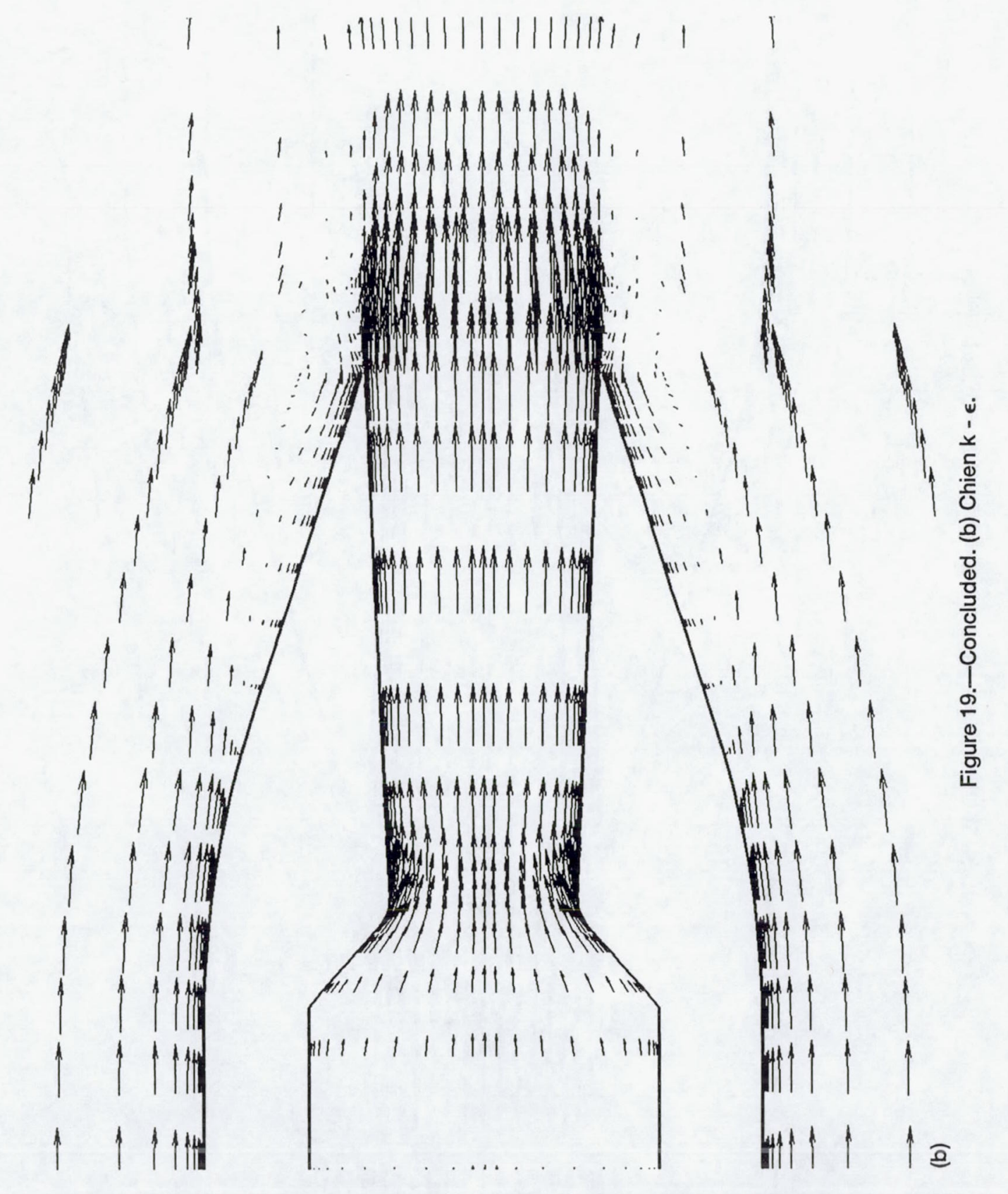




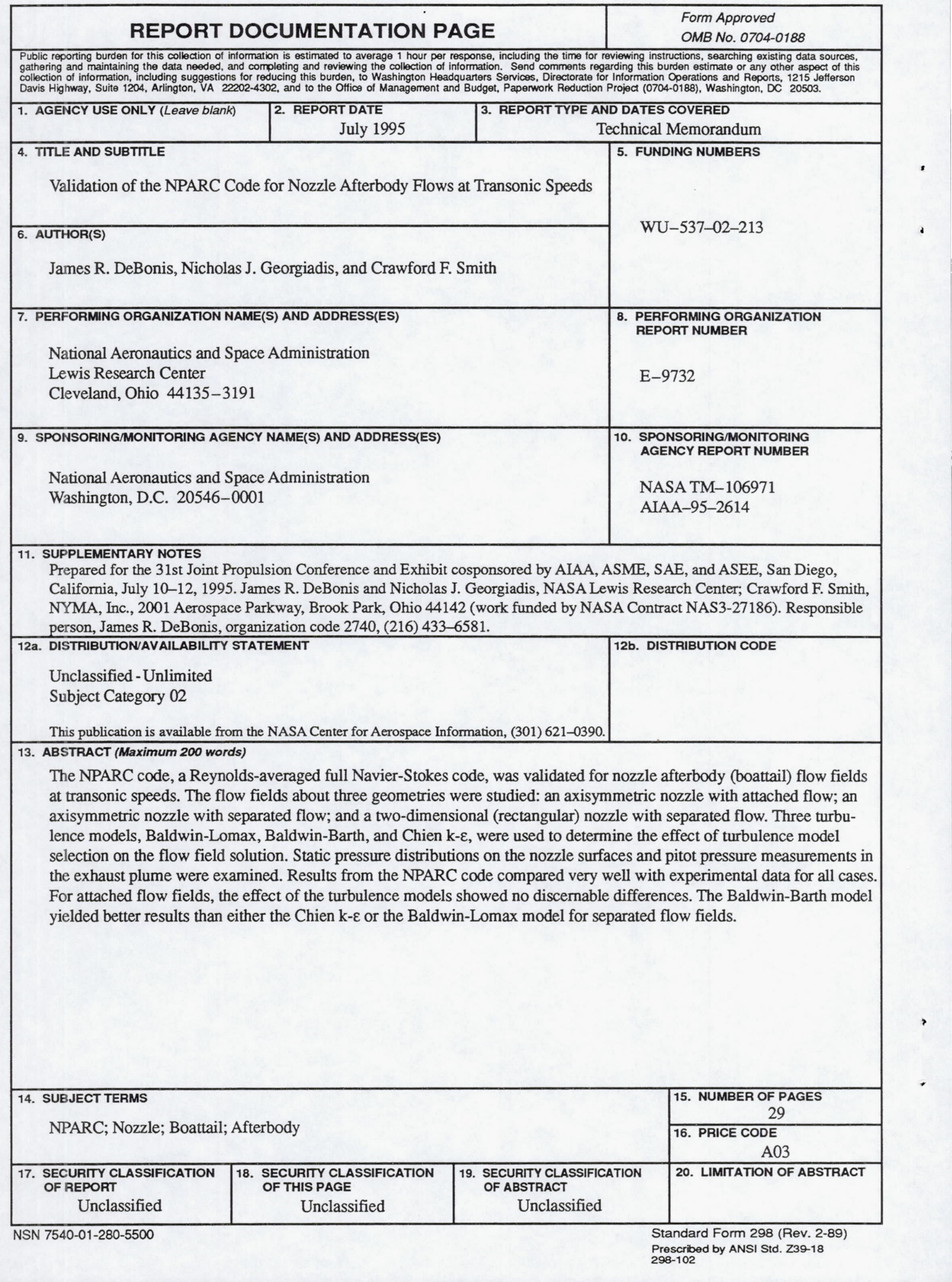

